\title{
ESCLAVITUD Y TRÁFICO DE ESCLAVOS EN EL PACÍFICO SURAMERICANO DURANTE LA ERA DE LA ABOLICIÓN*
}

\author{
Marcela Echeverri \\ Yale University
}

INTRODUCCIÓN

Tan inextricable es el abismo de la esclavitud, en que no se puede entrar sin encontrar precipicios por cualquier sendero que se tome.

Gerónimo Torres, 1822

T a República de Colombia se fundó sobre la base de una L política abolicionista gradual que quedó plasmada en su primera carta Constitucional, la Constitución de Cúcuta de 1821. En la región norte de Suramérica, la participación de esclavos y gente libre de color en los ejércitos de la independencia tuvo

Fecha de recepción: 3 de mayo de 2018

Fecha de aceptación: 8 de octubre de 2018

* La autora agradece el apoyo en la investigación de Julissa Gutiérrez y Ramiro Sánchez, así como los comentarios de Alex Borucki, Celso Castilho, Keila Grinberg, Michelle McKinley, de los participantes del Atlantic History Workshop en New York University y del Race and Slavery Working Group en Yale University y de los evaluadores del texto para Historia Mexicana. 
como consecuencia que el proyecto de construcción de la nación independiente -la cual en 1821 incluía a las actuales Venezuela, Ecuador y Panamá- estuviera profundamente imbricado con los intereses de las poblaciones afrodescendientes que buscaban garantizar sus derechos dentro del nuevo marco político. Además, con las leyes de libertad de vientres, la creación de juntas de manumisión y la abolición del tráfico de esclavos, Colombia estuvo en la vanguardia del abolicionismo en el mundo atlántico, a la par con las demás repúblicas de la América española continental y con Haití, especialmente en cuanto a experimento republicano que materializó la relación entre el discurso de la libertad y la emancipación de los esclavos.

Sin embargo, muy pronto el proyecto abolicionista se vio truncado por los intereses de las clases esclavistas, en especial las que habían fundado su poderío económico en la extracción de oro en la costa pacífica de la provincia de Popayán. Familias prominentes entre las cuales se encontraban los Mosquera, Arboleda, Torres y Arroyo ejercieron resistencia durante los primeros diez años de la independencia de Colombia, saboteando la implementación de las leyes de manumisión. En la década de 1840, cuando ya el país se había fragmentado y Popayán estaba dentro de la Nueva Granada, las élites payanesas lograron que el gobierno volviera a instaurar el tráfico de esclavos y trasladaron grandes números de esclavizados hacia Panamá, desde donde los vendieron a agentes peruanos y estadounidenses. A pesar de constituir una afrenta al proyecto republicano que surgió de la revolución de independencia, los dueños de esclavos justificaron sus acciones usando una retórica constitucional. Es decir, plantearon que sus intereses eran equivalentes a los del Estado $\mathrm{y}$, aprovechando su poder político, actuaron para modificar la ley dentro del mismo.

Este artículo trata la historia de la reapertura del tráfico de exportación de esclavos en la Nueva Granada entre 1843 y 1847 a través del puerto de Buenaventura en el Pacífico. El episodio 
muestra que, en Suramérica, a raíz de las luchas económicas y políticas a favor y en contra de la esclavitud, las aboliciones no tuvieron resultados lineales. A partir de un análisis de las relaciones entre las siguientes cuestiones -1 . la formación del Estado y el poder regional de las élites esclavistas y 2. el tráfico de esclavos en el Pacífico y las redes económicas y políticas hemisféricas- entendemos mejor por qué la abolición fue un proceso conflictivo en Colombia, a pesar de los principios abolicionistas escritos en su constitución. Específicamente, las luchas en torno a la abolición de la esclavitud fueron parte de la formación del Estado colombiano/neogranadino en tres dimensiones: las disputas regionales, la definición de la ciudadanía, y las alianzas y tensiones internacionales. Mi argumento es que, visto a través de la historia de Popayán, estudiar la emergencia, circulación y puesta en práctica de las ideas a favor de la esclavitud constituye una nueva perspectiva clave sobre el proceso de formación del Estado en Hispanoamérica.

El objetivo del artículo también es contribuir al debate sobre la abolición de la esclavitud en el mundo atlántico expandiendo la frontera del análisis hacia el Pacífico, mostrando cómo las nuevas repúblicas del mundo andino formaban parte de una red de ideas y de comercio que integraba a América del Norte con América del Sur. Las presiones que las élites de Popayán ejercieron sobre el gobierno nacional en Bogotá para legalizar el comercio de esclavos en la década de 1840 se apoyaron estratégicamente en sus conexiones con élites peruanas que en ese mismo momento estaban invirtiendo en fortalecer la economía de plantaciones al norte del Perú. Así mismo, las familias Mosquera y Arboleda establecieron vínculos comerciales con compañías de Estados Unidos que desarrollaron el proyecto de construcción del ferrocarril en Panamá. ${ }^{1}$

1 Castrillón, Tomás Cipriano de Mosquera; Castellanos, La abolición de la esclavitud en Popayán. 
En ese sentido, la historia de la abolición en Colombia, vista en un contexto hemisférico, nos habla de la manera en que los proyectos económicos y políticos republicanos, tanto como la historia de las migraciones forzadas de afrodescendientes en esta región (el tráfico de esclavos dentro de las Américas), deben analizarse en un marco transnacional. Desde esa perspectiva podemos ver las contradicciones del proceso de abolición a través de varios lentes complementarios y exponer los vínculos de distintos intereses con el proceso de transformación legal, económico, social y político que implicó desarticular las economías esclavistas. Es fundamental remarcar estos puntos en conjunto para demostrar que el estudio de las aboliciones hispanoamericanas representa un espacio de debate urgente en el contexto de las historiografías de la abolición, tanto específicamente en Latinoamérica como a nivel global.

\section{CONTEXTO ATLÁNTICO DE LA ABOLICIÓN \\ DE LA ESCLAVITUD EN HISPANOAMÉRICA}

Durante las guerras de independencia a lo largo del territorio hispánico en la América continental que dieron lugar a las repúblicas latinoamericanas, guerras que comenzaron en $1810 \mathrm{y}$ terminaron entre los años 1820 y 1825, se generaron lazos entre el republicanismo y la abolición de la esclavitud. ${ }^{2}$ Esa asociación

2 Blanchard, Under the Flags of Freedom. Sobre la abolición en Perú véase Aguirre, Agentes de su propia libertad; Blanchard, Slavery and Abolition in Early Republican Peru; Hünefeldt, Paying the Price of Freedom; Tardieu, El decreto de Huancayo. En Venezuela, véase Lombardi, The Decline and Abolition of Negro Slavery in Venezuela. En Colombia, véase BIERCK Jr., "The Struggle for Abolition in Gran Colombia"; Tovar y Tovar, El oscuro camino de la libertad; Pita Pico, La manumisión de esclavos en el proceso de independencia de Colombia. En Ecuador, véase Tobar Donoso, "La abolición de la esclavitud en el Ecuador"; Townsend, "En busca de la libertad". En Chile, Feliú Cruz, La abolición de la esclavitud en Chile. En Panamá, véase McGuiness, Path of Empire. Para México Baumgartner, "Abolition from the South". 
entre republicanismo y abolición en Hispanoamérica no fue, del todo, una innovación en su tiempo. En la colonia francesa de Saint Domingue en 1804 los vencedores de la guerra de independencia contra Francia crearon la República de Haití y abolieron la esclavitud. La gran particularidad de esa guerra que culminó con la independencia y la fundación de la República de Haití fue que estuvo liderada por gente africana y afrodescendiente. Por eso la abolición de la esclavitud en ese contexto, y como resultado de una larga guerra, tuvo un gran peso simbólico en la manera como se entendió a partir de entonces, en el mundo atlántico, la fuerza y la visión política de los esclavizados. También demostró los límites de la esclavitud como sistema de producción colonial con vínculos con mecanismos de dominación racial que se venía desarrollando a favor de las economías europeas. ${ }^{3}$

Desde el siglo xviII se intensificaron los debates en el mundo atlántico sobre los horrores de la esclavitud, repensando sus justificaciones sobre todo en Francia, Estados Unidos y Gran Bretaña. Luego, como se ha dicho, la revolución en la isla francesa de Saint Domingue hizo incuestionable la posibilidad de que fuerzas afrodescendientes atacaran y destruyeran la institución, generando fuertes dudas sobre su sostenibilidad. En el contexto del Atlántico hispánico la abolición fue un tema que había tenido menos discusión. Más aún, en el último cuarto del siglo XVIII, contrario a las ideas abolicionistas, España intensificó su inversión en la trata de africanos y en la expansión de la economía azucarera. Ese compromiso se solidificó durante los debates de las Cortes de Cádiz, a pesar de que algunas voces presentaron propuestas para abolir la esclavitud. ${ }^{4}$

\footnotetext{
En Argentina, Andrews, The Afro-Argentines of Buenos Aires. Para Uruguay, véase Borucki, Abolicionismo y tráfico de esclavos en Montevideo.

${ }^{3}$ Dubois, Avengers of the New World; Trouillot, Silencing the Past.

${ }^{4}$ Incluido el neogranadino Antonio Villavicencio, quien fue comisionado a la Regencia y llevó un proyecto de abolición de la esclavitud. URIBE-URán, Honorable Lives. Dos textos sintéticos sobre el abolicionismo temprano
} 
En contraste con la política española, y con los proyectos nacionales que predominaron en Estados Unidos y Brasil durante gran parte del siglo XIx, las medidas abolicionistas de las repúblicas hispanoamericanas entre 1810 y 1820 representaron un verdadero experimento. La promulgación de legislación abolicionista fue un acto que marcó una diferencia, una oposición, a la España imperial que había gobernado por medio de la esclavitud durante siglos. Simultáneamente, esa legislación representó una dimensión del "nuevo poder" soberano del Estado republicano para ejercer su autoridad de reinventar las sociedades americanas, deshaciéndose de uno de los más evidentes legados coloniales. ${ }^{5}$

La especificidad de las repúblicas latinoamericanas estuvo en que éstas fueron el producto de alianzas entre los criollos, que eran descendientes de los antiguos colonizadores europeos y la clase privilegiada en la América española, y los sectores populares, que incluían las poblaciones indígenas, mestizas y afrodescendientes, tanto esclavizadas como libres. A raíz de esas alianzas, una guerra anticolonial que expulsó a los europeos del poder dio lugar a repúblicas que se basaron en principios igualitarios. ${ }^{6}$

en Francia, Estados Unidos y Gran Bretaña y sus desarrollos en el mundo Atlántico son Blackburn, The American Crucible y Drescher, Abolition. Para Estados Unidos específicamente, véase NASH y Soderlund, Freedom by Degrees. Sobre las particularidades de la esclavitud y el abolicionismo en el mundo hispánico, véase Berquist, "Early Antislavery Sentiment in the Spanish Atlantic World"; EcheverRI, "Slavery in Mainland Spanish America in the Age of the Second Slavery"; Ferrer, Freedom's Mirror; Fradera y SCHMIDT-NOWARA (coords.), Slavery and Antislavery in Spain's Atlantic Empire. ${ }^{5}$ Simon, The Ideology of Creole Revolution.

${ }^{6}$ Lasso, Myths of Harmony trata el surgimiento de valores de armonía racial en Cartagena. Sobre la participación de los esclavos en la independencia, véase Blanchard, Under the Flags of Freedom; BRAGONI, "Esclavos insurrectos en tiempos de la revolución"; ECHEVERRI, Indian and Slave Royalists in the Age of Revolution; Goldberg, "Afrosoldados de Buenos Aires"; Mata, "Negros 
Destruir o desarticular la institución esclavista no fue un proceso fácil ni lineal. En un principio, el proceso militar demostró la urgencia de incorporar a la gente afrodescendiente al proyecto independentista. Por eso se otorgó la libertad a los esclavos en casos individuales, como recompensa por los sacrificios militares. Después de la independencia, las nuevas repúblicas en su mayoría legislaron a favor de una abolición gradual de la esclavitud, integrando en sus constituciones leyes de libertad de vientres, de abolición del tráfico esclavista y para la creación de juntas de manumisión. A todas luces, estos fueron pasos importantes hacia el "fin" de la historia de la esclavitud africana, un proceso que por supuesto implicaba una transformación -una verdadera revolución- en términos de los fundamentos económicos y políticos de las sociedades hispanoamericanas. En todas, sin excepción, desde México hasta el Río de la Plata y Chile, la esclavitud había sido parte fundamental, estructurante; había definido tanto las relaciones sociales como las dinámicas económicas desde la llegada de los europeos a América en el siglo xv. Y por esto es natural que en todos los casos hubo resistencia por parte de los sectores criollos que veían peligros, para sus intereses de clase, en tales decisiones y las transformaciones radicales que conllevarían.

En el caso de la República de Colombia, fundada en 1821, el proyecto de abolir la esclavitud se relacionó íntimamente con el precedente haitiano. Es más, la diplomacia abolicionista de Haití fue un factor decisivo que puso la abolición de la esclavitud entre las prioridades de los líderes suramericanos patriotas, especialmente Simón Bolívar. ${ }^{7}$ Así mismo, la primera República de Colombia es perfectamente ilustrativa de este importante proceso hispanoamericano y de la relación inestable entre el

y esclavos en la guerra por la independencia”; RUEDA, “Territorio, movilización e identidad étnica".

7 Ferrer, "Haiti, Free Soil, and Antislavery in the Revolutionary Atlantic", pp. 60-61; Fischer, "Bolívar in Haiti”; Verna, Pétion y Bolivar. 
proyecto del Estado abolicionista y las diferentes demandas sociales y políticas sobre las cuales se erigió. La abolición dependía de las estructuras del Estado y, a la vez, era un mecanismo de institucionalización de burocracias que permitía la creación o construcción del Estado en los espacios local, regional y nacional. Como tal, el proyecto de abolición de la esclavitud fue en esencia volátil. Además, como proyecto liderado desde la capital de la República, la abolición de la esclavitud también tuvo visos de imposición, como una decisión tomada "desde arriba"; un instrumento de centralización del poder. En Colombia fue Simón Bolívar quien sobresalió como símbolo inspirador, pero también impositor, de esa medida.

Como se ha dicho, es un hecho que Bolívar tomó esa decisión a raíz de su negociación con el presidente de Haití, Pétion, quien le ofreció su apoyo militar con la condición de que el movimiento andino independentista fuera además un proyecto abolicionista. También está claro que la política militar de Bolívar tomó giros pragmáticos una vez que éste se dio cuenta de que era necesario ganarse el apoyo de las poblaciones afrodescendientes para que éstas no estuvieran del lado de los realistas (como lo estuvieron, en su mayoría, tanto en Nueva Granada como en Venezuela, durante la guerra de independencia). En realidad, entonces, Bolívar respondió a presiones tanto internas como externas. ${ }^{8}$

La nueva historiografía sobre el tema de la abolición en Colombia se ha desarrollado a partir del reconocimiento de estas dos fuerzas, la movilización de la población afrodescendiente en los ejércitos y la negociación con Haití. A éstas debemos añadir la dimensión estratégica de oponerse a la política esclavista de España. ${ }^{9}$ Y estudiar este tema mediante estas tres perspectivas

8 Véanse Lynch, Simón Bolivar, p. 108; Peru de Lacroix, Diario de Bucaramanga, p. 59.

9 Bassi, An Aqueous Territory; Blackburn, "Haiti, Slavery, and the Age of Democratic Revolution"; Blanchard, Under the Flags of Freedom; 
nos obliga a enfrentar la noción antigua de que fueron los británicos quienes ejercieron la influencia necesaria para iniciar y llevar a cabo los procesos abolicionistas latinoamericanos. ${ }^{10}$

Visto de tal manera, tradicionalmente se ha supuesto que esos procesos eran un apéndice de la política británica imperial y de Gran Bretaña, a partir del comienzo del siglo xix, como gestora del movimiento abolicionista que difundió la crítica moral de la esclavitud en las sociedades del mundo atlántico, transformando la economía global radicalmente. Pero, como dijo James Ferguson King hace varias décadas, si bien el tema de la abolición de la trata fue un punto central en los tratados de comercio y navegación que firmó Gran Bretaña con las repúblicas independientes, fue después de 1830 cuando se volvió un punto condicional para el reconocimiento de las repúblicas. $\mathrm{La}$ abolición de la trata en la América hispana continental en realidad precedió tales negociaciones pues tuvo su origen durante los procesos de independencia. Por esto, es un error adjudicarle a la presión de Gran Bretaña el lugar de iniciadora del proceso abolicionista en la América española como única explicación. ${ }^{11}$

Por otra parte, esa lectura que sobreenfatiza la presión británica asume que Inglaterra fue, durante el siglo XIX, únicamente un símbolo de oposición a la esclavitud, borrando las complejidades y contradicciones del proceso abolicionista en el mismo imperio británico. Además, si bien el tema diplomático o internacional es crucial en la historia de la abolición latinoamericana, no lo es solamente en relación con la Gran Bretaña. ${ }^{12}$ Como

ECHEVERr, Indian and Slave Royalists in the Age of Revolution; Drescher, Abolition, pp. 169-80; Ferrer, Freedom's Mirror; FisCHer, "Bolívar in Haiti"; Helg, Liberty and Equality in Caribbean Colombia; Verna, Pétion y Bolivar. 10 Clementi, La abolición de la esclavitud en América Latina.

${ }^{11}$ KIng, "The Latin-American Republics and the Suppression of the Slave Trade," p. 391.

${ }^{12}$ Sobre la complejidad del proceso abolicionista británico, véase DRESCHER, Abolition; Dumas, Proslavery Britain; Huzzey, Freedom Burning; Temperley, British Antislavery, 1833-1870; Marquese, Parron y Berbel, Slavery 
mostraré a continuación, deben reconocerse otras relaciones diplomáticas y comerciales contemporáneas entre las repúblicas americanas, fundadas en intereses pro-esclavitud. Efectivamente, la perspectiva anglocéntrica también desconoce los procesos regionales que caracterizaron la construcción de los Estados hispanoamericanos después de la independencia. Es decir, oscurece la forma en que dinámicas esenciales de la integración regional y la construcción de la ciudadanía también estuvieron ligadas a la abolición de la esclavitud en América Latina. ${ }^{13}$

Por último, la historiografía que se ha desarrollado recientemente sobre la "segunda esclavitud", la cual se enfoca en los procesos de expansión y abolición de la esclavitud en Cuba, Estados Unidos y Brasil, ha demostrado la importancia de entender las transformaciones de la institución de la esclavitud en el momento del auge del liberalismo y del abolicionismo. Los trabajos sobre estos casos señalan, en particular, que el tráfico ilegal de esclavos en el Atlántico es parte importante del fortalecimiento de las economías esclavistas en el siglo XIX. Sin embargo, los historiadores que trabajan en este campo han desconocido los desarrollos paralelos que tuvieron lugar en la región continental de la América española. El estudio que presento en este artículo demuestra que esa omisión es problemática porque los procesos de abolición, defensa de la esclavitud y tráfico ilegal de esclavos fueron comunes a las repúblicas hispanoamericanas. Estos últimos casos son igualmente relevantes como precedentes y experimentos paralelos a lo que sucedió en Cuba, Estados

and Politics, p. 181, quienes señalan que antes de que comenzara la abolición de la esclavitud en las colonias británicas del Caribe (1833-1834), los esclavistas cubanos se apoyaban en el ejemplo británico como un modelo de gobierno colonial que haría viable el mantenimiento de la esclavitud en el Imperio español. 13 Un trabajo sobre la abolición de la esclavitud y la emergencia de la ciudadanía en Brasil que ha sentado las bases conceptuales para esta discusión es Castillo, Slave Emancipation and Transformations in Brazilian Political Citizenship. 
Unidos y Brasil. Además, estuvieron conectados -comercial e ideológicamente- con estas mismas regiones. También ilustran que las tensiones políticas a favor de la expansión de la esclavitud o de su abolición, características de esos casos mejor conocidos, fueron parte esencial de la historia de las repúblicas hispanoamericanas en el proceso de formación del Estado después de la independencia. ${ }^{14}$

\section{ESCLAVITUD Y FORMACIÓN DEL ESTADO \\ EN LA NUEVA GRANADA}

Nada hay peor que este pobre Sur, mientras los bogotanos no nos crean iguales a ellos en todo. ${ }^{15}$

En la Nueva Granada la resistencia más fuerte contra las leyes de abolición gradual provino de los esclavistas en el Suroccidente, en la provincia de Popayán. Esa resistencia comenzó poco tiempo después de la independencia (en el contexto colombiano) y duró incluso hasta los años posteriores a la abolición final en 1852. Los esclavistas se pronunciaron frente al gobierno central con sus críticas y ofreciendo alternativas con las que buscaban intervenir en la legislación, es decir, reformas a la ley que protegieran sus intereses. También desplegaron variadas estrategias por medio de las cuales lograron sabotear la aplicación de la ley y, por un periodo corto, detenerla.

${ }^{14}$ La historiografía sobre la "segunda esclavitud" incluye FERRER, Freedom's Mirror; Marquese, Parron y Berbel, Slavery and Politics; Tomich (coord.), The Politics of the Second Slavery; KaYe, "The Second Slavery". Un desarrollo más extenso de mis argumentos sobre la importancia del diálogo entre esta historiografía y la historia de la esclavitud y la abolición en las repúblicas hispanoamericanas se encuentra en Echeverri, "Slavery in Mainland Spanish America in the Age of the Second Slavery".

15 Vicente Javier Arboleda a T. C. de Mosquera, Popayán, 17 de enero, 1843. ACC, SM, 17,009. 
Durante el periodo colonial, Popayán era una provincia muy extensa que incluía la región pacífica de Nueva Granada. Esta provincia fue central para la economía del Imperio español gracias al trabajo de esclavizados traídos de África a trabajar en minas de oro y en haciendas. Los esclavistas de la región, o "dueños de esclavos" como se llamaban ellos mismos, habían construido su riqueza y su poder sobre la explotación del oro, economía que se articulaba con la producción en las haciendas del interior de la provincia. Después del ordenamiento territorial y el ajuste de las jurisdicciones tras la independencia, la gran provincia de Popayán se dividió en las provincias de Buenaventura, Cauca, Chocó, Pasto y Popayán. Además, es importante recordar que la región de Esmeraldas, al sur de Popayán, que dependía de la Audiencia de Quito y donde también trabajaban cuadrillas de esclavos en la extracción de oro, estaba estrechamente ligada a Popayán mediante relaciones comerciales y de parentesco tanto entre las élites como en las comunidades de negros libres y esclavizados. En lo que sigue me referiré al conjunto de estas provincias como el Sur o el Suroccidente, términos que se usaron históricamente para describir la región. ${ }^{16}$

Las familias esclavistas del Suroccidente solidificaron su poderío económico y político por medio de su participación en el gobierno desde el contexto colonial y durante la guerra de independencia. Cuando Simón Bolívar llegó a la región en 1822, negociaron con él y sus representantes para asegurarse de que mantendrían ese lugar privilegiado dentro del marco republicano. Sin embargo, ya desde esa época desarrollaron un resentimiento con el gobierno bolivariano porque en las guerras de independencia tuvieron que ceder parte de sus esclavos para

16 Colmenares, Historia económica y social de Colombia; Díaz, "El Cauca Grande"; Marzhal, "Creoles and Government”; Mcgreevy, An Economic History of Colombia; SAFFORD, "Social Aspects of Politics in NineteenthCentury Spanish America"; SHARP, Slavery on the Spanish Frontier; WEST, Colonial Placer Mining in Colombia. 
los ejércitos. También vieron sus propiedades afectadas por el desorden que generó la guerra y, para hacer las cosas peores, los esclavos de la región aprovecharon la coyuntura para enfrentarse a sus amos, escapar o vivir en libertad en las minas. ${ }^{17}$

En el corazón de estas tensiones que surgieron durante la guerra de independencia estaba la pugna de intereses entre el gobierno central en la capital de Bogotá y las élites políticas y económicas del Suroccidente que se veían en algunos momentos marginadas del gobierno y, en otras, simplemente ignoradas en sus intereses y peticiones. La visión de las élites payanesas se materializó alrededor del puerto colombiano más importante en el Pacífico, Buenaventura, por medio del cual Cali y Popayán, las ciudades más importantes del Sur, se conectaban con Panamá y Guayaquil, y otros puertos en Perú y Chile. En 1822, cuando se creó la provincia de Buenaventura con capital en Iscuandé, el primer gobernador fue Tomás Cipriano de Mosquera. Desde allí, Mosquera tuvo influencia sobre los procesos económicos y políticos que tuvieron lugar en la región minera del Pacífico. Esto incluyó promover relaciones comerciales con inversionistas europeos y también proyectar la expansión del poder de las élites de Popayán y Cali hacia el Pacífico.

En lo relativo al tema de la esclavitud, que estuvo íntimamente ligado a los intereses de importantes políticos colombianos (neogranadinos) que provenían de Popayán, los activistas que ocuparon posiciones en el gobierno, tanto en el ámbito regional como en el nacional, promovieron su visión en función de los intereses de una clase que no se pensaba quedar con los brazos cruzados ante la situación de cambio radical que trajo el proyecto abolicionista del Estado republicano. Mediante su participación en éste desde dentro, en el Congreso, podían actuar frente a su

17 Echeverri, Indian and Slave Royalists in the Age of Revolution; Lynch, Simón Bolivar; Prado y Prado-Valencia, "La familia Mosquera y Arboleda y el proyecto bolivariano (1821-1830)". 
insatisfacción con las medidas del Estado, y ese era un esfuerzo que potencialmente podía tener resultados a su favor (por ejemplo, cuando lograron institucionalizar cambios como la apertura de la trata de esclavos en 1843, como veremos).

Los dueños de esclavos también ejercieron resistencia por fuera de las instancias legislativas, en una dimensión más cotidiana, frenando la ejecución de las medidas para la creación y el funcionamiento de las juntas de manumisión. Las quejas administrativas que llegaban a la capital -desde Venezuela, Quito, Panamá y varios otros lugares dentro de la Nueva Granada- demostraban que había problemas en la interpretación de las leyes. Entre otras cosas, los miembros de las juntas de manumisión señalaron en varios casos las recurrentes estrategias de evasión por parte de las familias cuyas testamentarias eran el objeto del impuesto para financiar las manumisiones. Así que las dudas frente a la aplicación de la ley, y la capacidad que tenían los dueños de esclavos de evadirla, fueron una fuente más de inestabilidad para el sistema de abolición gradual que se había iniciado en $1821 .^{18}$

La ley de manumisión del 21 de junio de 1821 se publicó en Popayán el 8 de septiembre de dicho año. ${ }^{19}$ Tal como sucedió en otros lugares de Colombia, por ejemplo en Venezuela, los esclavistas de Popayán resintieron lo que veían como una política imprudente. Por una parte, su reacción demuestra que ellos percibían esa medida como una intromisión. Sus argumentos también revelan que, para los grandes propietarios de esclavos, como las familias Torres, Arboleda y Mosquera, el proyecto abolicionista tenía graves fallas.

18 Véase, por ejemplo, la queja proveniente de Panamá (1825), en AGNC, SR, Congreso, leg. 27, ff. 233-243. También la de Mariquita en AGNC, ALC, E1CA-B6, Cámara, Decretos 1834, fol. 73. Algunas de Popayán se encuentran en ACC, AM, 1838, p. 28 legs. 32-52; y para Venezuela véase LoMBARDI, The Decline and Abolition of Negro Slavery in Venezuela.

19 ACC, AM, legs. 32-52, doc. 45, 18 de marzo de 1838. 
Con la intención de moldear el proyecto desde su perspectiva como grandes esclavistas, éstos se movilizaron desde el Congreso para proponer reformas a la ley. Dos de los representantes de esa clase fueron Gerónimo Torres y Joaquín Mosquera. Ambos publicaron sus discursos al Congreso. Esos textos nos permiten conocer la manera en que los esclavistas payaneses veían el proceso de abolición de la esclavitud en la Colombia temprana. ${ }^{20}$

En común tienen estos políticos, como Torres y Mosquera, que se aseguraron de calificarse como hombres ilustrados en el debate abolicionista de su tiempo, utilizando un lenguaje cosmopolita con el cual demostraban que no estaban en la periferia de las discusiones internacionales sobre la esclavitud y la abolición. Por ejemplo, en textos de economía política liberal, o en los debates parlamentarios británicos, ellos buscaban los argumentos que más se acoplaban a sus propios intereses y perspectivas. Es por esto que sus posiciones se asemejaban a lo que Paula Dumas, para el contexto británico, llama la ideología "anti-abolición", que se caracterizaba por desarrollar discursos a la defensiva de lo que se vislumbraba como la legislación abolicionista. Sin embargo, también hay importantes diferencias. Los debates sobre la abolición de la esclavitud en el imperio británico tuvieron lugar inicialmente en un momento previo a la declaración de tales leyes, y por lo tanto esas leyes fueron producto de las negociaciones entre los distintos intereses. En el caso colombiano, las élites esclavistas tenían que oponerse a una visión que ya había tomado la forma de legislación desde la creación de la república, presumiblemente sin su aprobación. Además, en el imperio británico lo que estaba en juego era la

${ }^{20}$ Análisis previos de los proyectos se encuentran en el clásico Jaramillo URIBE, "La controversia jurídica y filosófica librada en la Nueva Granada", y más recientemente BEDOYA BETANCUR, "La controversia entre la esclavitud y la libertad". Estudios comparativos sobre el activismo de los esclavistas en Estados Unidos, Cuba y Brasil son Genovese, The Slaveholders' Dilemma y Marquese, Parron y Berbel, Slavery and Politics. 
posición colonial de las élites del Caribe, mientras en Colombia se estaba disputando la autoridad del Estado republicano independiente sobre las regiones. ${ }^{21}$

La propuesta de Torres data de 1822, es decir, sólo un año después de que se legalizó el proyecto abolicionista. Torres habló en un tono con el que no antagonizó con el gobierno. Por el contrario, expresaba la importancia de repensar los lineamientos de una ley que, según él, no se había preparado con base en un análisis previo. Una ley que tenía un espíritu valioso, pero que se planteaba metas imposibles. También remarcó el problema de la viabilidad de tal plan de abolición gradual, teniendo en cuenta datos y cálculos específicos sobre los cuales elaboró una nueva propuesta.

Torres abría su discurso reconociendo que Colombia era pionera en la legislación abolicionista, yendo más allá de "las naciones europeas” (refiriéndose específicamente a Gran Bretaña), donde los Estados solamente se habían limitado a abolir el tráfico de esclavos. Sin embargo, planteaba una perspectiva trágica sobre la situación, lamentando que ésta parecía no tener solución posible por estar basada en un problema tan complejo como la institución de la esclavitud: “Tan inextricable es el abismo de la esclavitud, en que no se puede entrar sin encontrar precipicios por cualquier sendero que se tome”. ${ }^{22}$

Torres argumentó que las faltas de la historia del colonialismo no podían cobrársele a los dueños de esclavos que habían heredado esa posición dentro de una sociedad que ellos mismos no habían creado. Y eran precisamente los derechos de los esclavistas los que iba a defender. Es interesante que, aunque desde una perspectiva moral decía estar de acuerdo con la crítica a la esclavitud (a la que llamaba antinatural), aclaraba que no

${ }^{21}$ Dumas, Proslavery Britain, pp. 11-12.

22 Torres, Observaciones, BNC, $P$, 309, pieza 15, pp. 7-8. 
se trataba de apelar "al tribunal de la naturaleza, porque ahora discutimos delante del de la política". ${ }^{23}$

Las palabras de Torres permiten ver cómo se formulaban argumentos que no defendían la esclavitud, pero sí los intereses de los esclavistas, planteándolos como equivalentes a los intereses del Estado colombiano. Decía, por ejemplo: "yo creo que el vehemente deseo de hacer el bien ha turbado en su mano la balanza en perjuicio del propietario y también con detrimento de la República". ${ }^{4}$

Uno de los ejes de la crítica era que el problema de la ley estaba en declarar libres a los hijos de los esclavos, aquellos que estaban amparados bajo la libertad de vientres, sin compensar a los amos por su propiedad. Torres señalaba que la inversión de la esclavitud presuponía la capacidad de reproducción de los esclavos y que negar esa posibilidad era ya una afrenta contra los dueños de esclavos. Para hacer las cosas peores, tenían ellos mismos que pagar la liberación de los esclavos pues los fondos para las manumisiones se extraían justamente de sus testamentarias, según el diseño de la codificación. ${ }^{25}$ "Seamos justos con los esclavos sin dejar de serlo con los amos", insistía.

Los puntos de la propuesta eran:

1- Declare el Congreso la libertad absoluta de los noventa mil esclavos que tiene actualmente Colombia. 2- Reconozca como deuda nacional los 18 millones de su valor en favor de los dueños. 3 - Pague religiosamente el interés de un $3 \%$ anual, hasta que pueda la República redimir el principal, y 4- Declare por ahora en estado de minoridad a los negros que acaba de libertar. ${ }^{26}$

${ }^{23}$ Torres, Observaciones, p. 14.

${ }^{24}$ Torres, Observaciones, p. 10.

${ }^{25}$ La ley se encuentra en Posada y Restrepo Canal, La libertad de los esclavos en Colombia, pp. 227-239.

26 Torres, Observaciones, pp. 15, 29. 
En contra de lo que podría esperarse, en el primer punto Torres planteó que lo ideal sería liberar a todos los esclavos de una sola vez, en lugar de seguir un proceso gradual (es decir, menos radical). Así, lejos de lo que podría asumirse que propondría un representante de los intereses esclavistas, oponerse a la abolición, Torres veía la posibilidad de la emancipación inmediata de los esclavos como algo aceptable y a la vez deseable en términos morales. Más aún, su propuesta era una solución al siguiente problema, que "los impuestos sobre las herencias destinados para la caja de manumisión, ni libertarán a la mayor parte de los infelices negros de su yugo, ni repararán a los amos la pérdida inevitable de su propiedad". ${ }^{27} \mathrm{Su}$ argumento articulaba de manera conciliatoria los intereses de los dueños de esclavos y de los esclavos mismos.

Otro aspecto singular que hace a Torres interesante como agente ideológico y político de los esclavistas payaneses es su argumento sobre la responsabilidad que tenía el Estado de otorgar a los emancipados un terreno y algún capital para que pudieran salir adelante económicamente. Más aún, una vez convertidos en agentes económicos autónomos, éstos podrían pagar un impuesto que, a su vez, sería una contribución a los recursos que el Estado debía invertir en la manumisión de los que continuaran esclavizados.

Este elemento de la propuesta sugiere que para los esclavistas una alternativa justa era compartir los costos de la manumisión con los mismos esclavos liberados. También ilustra su concepción de la población de negros libres como una colectividad que se asentaría en territorios colectivos, que éstos se integrarían a la economía, además de pagar impuestos al Estado. Esto debe analizarse a la luz de la importancia estratégica que tenían los deberes fiscales como mecanismos de garantía de derechos, con base en identidades legales sancionadas por el Estado. Es decir,

27 Torres, Observaciones, p. 23. 
debe recordarse que, tradicionalmente, el vínculo fiscal entre las comunidades de negros libres que surgieron en las Américas y el Estado fue fundamental dentro del contexto de la monarquía hispánica. ${ }^{28}$ Por eso, dado el caso de que se materializara tal propuesta, los afrodescendientes liberados podrían reclamar no solamente el derecho legal a la liberación de sus familias sino, también, alguna forma de ciudadanía. Efectivamente, Torres reconocía que "la manumisión absoluta eleva a los esclavos a la clase de ciudadanos, les da libertad, patria, nueva vida y existencia política". ${ }^{29}$ Por supuesto, es sensato asumir que esa fue la interpretación que los afrodescendientes libres, esclavizados, manumitidos y emancipados dieron al proceso de abolición. Resulta en cambio fascinante que Torres utilizara un lenguaje tan exaltado reconociendo los vínculos entre la libertad y la "existencia política", sobre todo porque sus ideas luego variaban para enfatizar que los esclavos eran hombres "indolentes, desidiosos por naturaleza, sin educación" y que "separados de la necesaria vigilancia de los amos, para el arreglo de su conducta, causaría un sacudimiento funesto a este cuerpo político". ${ }^{30}$

En este sentido, el último punto de la propuesta -"declare por ahora en estado de minoridad a los negros que acaba de libertar"- revela por qué, para Torres, como para todos los esclavistas de la época, era necesario mantener a los esclavos y sus descendientes en una categoría social aparte. Para justificar la necesidad de planificar su civilización añadió un elemento autobiográfico a su discurso diciendo que él mismo había visto lo perniciosas que eran las sociedades que construían los esclavos. Durante la crisis de la monarquía española, las cuadrillas de esclavos de Torres en el Pacífico habían estado a favor de los realistas, en una rebelión realista contra el bando independentista.

${ }^{28}$ Beatty-Medina, "Between the Cross and the Sword"; Gharala, Taxing Blackness; Landers, "Cimarrón and Citizen".

29 Torres, Observaciones, p. 29.

${ }^{30}$ Hombres es el término literal que usa Torres. Torres, Observaciones, p. 33. 
Mediante negociaciones con los agentes del rey lograron permanecer en libertad por casi una década. Esta situación no terminó con la independencia. Varios años después, en minas y haciendas, los esclavos del Cauca (donde se ubica Popayán) seguían fuera del control de sus amos. ${ }^{31}$

La flexibilidad y el sentido constructivo con los que Torres presentó la propuesta para reformar la ley de abolición no se mantuvieron por mucho tiempo, sin embargo y la intransigencia de los esclavistas se agudizó pocos años después. La familia Mosquera, cuyos intereses estaban especialmente atados a la esclavitud en sus propiedades en minas y haciendas, tuvo una presencia muy significativa en el Estado colombiano, con varios de sus miembros en el Congreso y en la presidencia representando los intereses payaneses. La más conocida participación fue del famoso Tomás Cipriano de Mosquera, que tuvo un papel fundamental en la guerra de independencia en el Suroccidente y fue presidente de la República varias veces entre 1845 y 1867.

La correspondencia entre los miembros de esta familia gira alrededor del tema de la esclavitud y su abolición, como cuando en julio de 1825 Manuel María Mosquera le comentaba a su hermano, Tomás Cipriano, que "Hoy se presentó en la asamblea electoral una memoria que ha escrito Joaquín impugnando la ley de manumisión". ${ }^{32}$ Se trataba de su hermano mayor, Joaquín Mosquera, quien volvió a poner en la mesa de discusión la reforma de la ley de manumisión. ${ }^{33}$ En lo esencial, se basó en la propuesta previa de Torres. En su discurso J. Mosquera decía:

${ }^{31}$ Entre las décadas de 1820 y 1850 los esclavistas se quejaron constantemente de la actitud rebelde de los esclavos que evidentemente estaba fundada en las perspectivas de la emancipación. ACC, Independencia, CIII-2g, 6596. ACC, SM, 2,023; ACC, AM, 1834, doc. 21. BLAA, AEDC, c. 8, carps. 84 y 87. ECHEVERri, Indian and Slave Royalists in the Age of Revolution.

${ }_{32}$ Manuel María Mosquera a T. C. de Mosquera, Popayán, 7 de octubre, 1825. ACC, SM, 2,072.

${ }^{33}$ Mosquera, Memoria. BNC, $P$, 687, pieza 8. 
"quiero que el bien se haga, quiero que los esclavos sean libres" y remarcaba que este era un "deseo" confirmado por "el respeto a la opinión de Simón Bolívar”. También, como Torres tres años antes, hacía un gesto de reconocimiento a las discusiones abolicionistas en otros países, pero consideraba innecesario repasarlas porque ya eran bien conocidas. Y añadía: "no pretendo oponerme a lo que ha sancionado la opinión universal". ${ }^{34}$

Es decir que J. Mosquera expresaba su lealtad al proyecto republicano, e incluso al proyecto abolicionista "universal", pero esperaba que sus propuestas como esclavista tuvieran un peso político en Colombia, dado el deber que tenía el Estado de proteger sus intereses. El tono de las críticas de J. Mosquera era mucho más negativo que el de Torres en 1822. Aunque en su preámbulo se planteaba a favor de la liberación de los esclavos, era tajante al decir que sabía que era urgente reformar la ley de manumisión de 1821 "pues aun su misma existencia es ya un mal". ${ }^{35}$

En materia económica, J. Mosquera planteó una crítica importante, en línea con lo que Dumas llama los argumentos legales e históricos que se desarrollaron en el contexto británico acerca de la abolición de la trata y de la esclavitud en las colonias del Caribe. ${ }^{36}$ Decía:

La esclavitud no ha sido otra cosa en los pueblos que hoy componen la República de Colombia (tomada económicamente) que la garantía que dio la nación a los propietarios de esclavos, de que el usufructo de sus obras sería perpetuo por medio de los partos. De aquí proviene que los esclavos han circulado en toda clase de contratos como un papel moneda garantizado o emitido por la nación. ${ }^{37}$

${ }^{34}$ Mosquera, Memoria.

${ }^{35}$ Mosquera, Memoria.

${ }^{36}$ Dumas, Proslavery Britain, pp. 24-32.

37 También mencionaba el ejemplo británico, en que "la prosperidad asombrosa de la Gran Bretaña, dice el célebre Smith, es debida exclusivamente al 
Aquí, J. Mosquera estaba defendiendo la necesidad de respetar la legalidad de un sistema económico y de propiedad que se remontaba a la relación colonial con España, cuando se había fundado el sistema esclavista, dentro del cual se habían modelado los derechos de los dueños de esclavos como él. Esta queja y el argumento sobre el cual se apoyaba es fundamental para entender la complejidad del proceso de abolición en materia económica y su percepción entre los dueños de esclavos. El debilitamiento y riesgo de disolución de los capitales de los esclavistas producto del proyecto revolucionario que implicó la abolición de la esclavitud fue un hecho evidente. A nivel más amplio, la reinvención de la propiedad representó uno de los ejes más radicales de la transformación legal parte de la construcción del Estado republicano y ese proceso afectó las relaciones sociales tanto objetiva como subjetivamente. Es decir, este fue un momento en que la noción de "clase" tomó forma discursiva y legal, por ejemplo, en la articulación de los esclavistas de su identidad política en esos términos, en conflicto con los intereses de su contraparte: la clase de los esclavos. ${ }^{38}$

La dinámica que históricamente se desarrolló en Popayán entre los representantes del Estado colonial, los esclavistas y los esclavos es justamente una pieza fundamental de esta historia que nos permite comprender por qué, para las élites, el proyecto de abolición gradual era profundamente desestabilizador. $\mathrm{Me}$ refiero a que los esclavos no eran simplemente objetos, como pretendían los esclavistas. Durante el gobierno español, los esclavos estaban siempre al tanto de la legislación y utilizaban las instituciones de la Monarquía para expandir sus derechos. Eran agentes políticos y sus intereses eran evidentes. Esto se agudizó

respeto con que se ha guardado la inviolabilidad de la propiedad". MosQuera, Memoria, pp. 19-20.

38 Sobre la importancia de estudiar la esclavitud y su abolición en su dimensión como derecho de propiedad, véase WRIGHT, Slavery and American Development. 
en las circunstancias de la fundación de la República de Colombia, momento crucial para su percepción de las oportunidades que conllevaba la abolición como proceso de cambio legal. ${ }^{39}$

Basados en su experiencia política y aprovechando la coyuntura de la guerra de independencia, durante la crisis de la Monarquía española los esclavos adquirieron poder colectivamente. Aunque a largo plazo no fue posible conseguir la libertad como comunidades, lograron en algunos casos controlar zonas estratégicas de extracción minera en el Pacífico. Para los esclavistas este fue un episodio dramático que demostró los riesgos de crecientes desórdenes en la región. Dio evidencia de la rapidez con que los esclavos en el Pacífico aprovechaban oportunidades para organizarse y asentarse en el territorio, formando comunidades y también desarrollando economías productivas..$^{40}$

Es decir, los esclavos no permanecieron inmóviles ni en silencio mientras el mundo a su alrededor se transformaba. Y, más importante aún, esos cambios no estaban sucediendo independientemente de la historia misma de las comunidades de esclavizados, quienes desde mucho tiempo atrás habían forjado espacios y prácticas de libertad. En el proceso de independencia, los esclavos se movilizaron y lograron concesiones significativas que los acercaron más que nunca a la noción de que tenían un poder de negociación frente al Estado. Por eso, para los dueños de esclavos era evidente que la legislación que se había inaugurado con la Constitución de Cúcuta en 1821 se convertiría en un arma para los esclavizados. Los esclavistas preveían que éstos invertirían sus energías en buscar formas de liberarse a sí mismos y a sus familias, no solamente cuestionando la autoridad de la clase de los dueños de esclavos sino, además,

39 Echeverri, Indian and Slave Royalists in the Age of Revolution; Pita Pico, La manumisión de esclavos en el proceso de independencia de Colombia. ${ }^{40}$ Por ejemplo, con un comercio de sales. Véase ACC, AM, 1834, doc. 27. ECHEVERrI, Indian and Slave Royalists in the Age of Revolution; Rueda, “Territorio, movilización e identidad étnica”, pp. 125-127. 
buscando la manera de ejercer presión frente al Estado desde sus propios intereses.

Esto ya se había visto desde el siglo anterior en el contexto del gobierno español. Las comunidades de libres en el Pacífico habían crecido a grandes pasos, a raíz del derecho a la autocompra. Con acceso al oro de las minas, éstos diseñaron mecanismos de extracción para sí mismos, con lo cual lograban ahorrar y progresivamente liberar a sus familiares. Este fenómeno se expandía hacia el sur de la Nueva Granada, en el Pacífico ecuatoriano, donde la zona minera de Popayán se conectaba con la región de Esmeraldas. ${ }^{41}$

En las minas del río Santiago en Esmeraldas, por ejemplo, los esclavos habían sido aliados de los insurgentes de Quito durante la guerra de independencia desde 1814. A pesar de la diferencia con lo que sucedió en Popayán, donde los esclavos del Pacífico fueron aliados de los realistas, la estrategia de movilizarse a favor del bando insurgente también abrió, para las cuadrillas de la familia Arroyo en Esmeraldas, oportunidades para vivir de manera autónoma durante más de una década. En 1825, sin embargo, sabemos que José Antonio Arroyo se quejaba, en una carta a T. C. de Mosquera, de la situación de descontrol que se vivía en sus minas y le contaba que estaba llevándose a los esclavos a $\mathrm{Pa}$ namá para venderlos. Es decir, que desde entonces los dueños de esclavos que tenían minas en Esmeraldas veían la venta de esclavos fuera del territorio como una solución al problema que enfrentaban, desde el tiempo de la guerra de independencia, para controlar a sus esclavos.

Sobre el intento de pacificación que hizo Arroyo en la mina del río Santiago sabemos también que en 1826 los esclavos enviaron a los capitanes de la mina a Quito -Fruto Arroyo, Cornelio Arroyo, Agustín Valencia y Guillermo Valencia- a denunciar

\footnotetext{
${ }^{41}$ Muchas de las minas de esa región eran propiedad de los esclavistas payaneses, como la familia Arroyo.
} 
los abusos a los que estaban siendo sometidos y además a pedir explícitamente la protección del gobierno colombiano. Los argumentos que estos esclavos utilizaron, y que el protector de esclavos presentó en el caso, demuestran que en 1826 los esclavos definían sus derechos y los deberes que tenían los dueños para con ellos aún en términos de la legislación colonial. Ellos citaron la Instrucción sobre la educación, trato y ocupaciones de los esclavos que había proclamado el gobierno borbónico en 1789 diciendo: "nosotros recomendamos a V. muy encarecidamente la observancia de la cédula sobre el tratamiento de los esclavos que tanto nos favorece". Como he demostrado en otro trabajo, aunque esta regulación fue revocada por la Monarquía poco tiempo después de que se proclamó, en realidad la Instrucción transformó las relaciones entre amos y esclavos en el Suroccidente neogranadino. Es más, su influencia en las estrategias legales de los esclavizados, tanto como dentro de las cortes, se comprueba una vez más en este caso. Los capitanes denunciaron la falta de cuidados físicos y espirituales que sufrían los esclavos en las minas. También señalaron que en el intento de pacificación de la familia Arroyo éstos habían enviado a un minero inglés, José Blar, y a un mayor, Tomás Gutiérrez, quienes eran extremadamente abusivos y violentos, sometiendo a los esclavos a castigos, robándolos y quemando sus casas. Los esclavos dijeron que merecían la protección del gobierno justamente porque habían sido leales a la causa de la república y habían hecho "gloriosos sacrificios en obsequio de la independencia”. También es importante que para los abogados ambos argumentos tenían valor y por eso decidieron "dictar las más urgentes providencias sobre los particulares que se indican, con lo que se aliviará aquella desgraciada casta de habitantes que reclama ante una autoridad benéfica y religiosa capaz de tan grande objeto". ${ }^{42}$

${ }^{42}$ ANE, Esclavos, c. 23, exp. 3, 10-IV-1826. RuedA, “Territorio, movilización e identidad étnica”, pp. 165-166. La Instrucción está publicada en KONETzKe, 
En vista del aumento de gente libre en la región, resultado del proceso que los esclavos estaban liderando tanto legalmente como por medio de acciones como las de la comunidad en Esmeraldas, el segundo punto más importante -aparte de la indemnización- que les preocupó a los esclavistas del Suroccidente, y que estaba al centro de sus denuncias en contra de la ley de manumisión, era el estatus social, político y económico de los manumisos. Plantearon sus ideas y objeciones frente a este tema en tres niveles: la obligación que tenían los dueños de las madres de educarlos; la manera en que la manumisión selectiva de individuos afectaba a la sociedad esclava negativamente; el diseño de instituciones que permitieran controlar a los manumisos y obligarlos a trabajar para beneficio de sus antiguos amos o del Estado.

En el punto relacionado con la integración de los manumisos a la sociedad, las élites en Popayán, como evidencian las familias Mosquera y Arboleda, estaban informadas sobre los experimentos que se llevaban a cabo en otras regiones esclavistas como Haití o Jamaica. En su discurso, J. Mosquera, por ejemplo, citaba el Acto para la protección, subsistencia, vestido y para el mejor orden y gobierno de los esclavos sancionado el 14 de diciembre de 1809 por la Asamblea de Jamaica. Lo citaba diciendo "me atrevo a recomendar su lectura a todos los amigos de los negros y del orden social", defendiendo la necesidad de reformar la educación de los esclavos y manumisos para hacerlos capaces de ser útiles a la sociedad desde antes de ponerlos en libertad. ${ }^{43}$

Gran parte del discurso de J. Mosquera, además, se enfocó en resaltar el carácter incivilizado, salvaje, de la gente afrodescendiente que habitaba la región pacífica de Colombia. También incluyó un punto ausente en el de Torres, sobre la importancia comercial de la región, y la tragedia que sería tener a los negros

Colección, pp. 643-652. Echeverri, "Enraged to the Limit of Despair".

${ }^{43}$ Mosquera, Memoria, p. 14. 
libres viviendo sin control en esa área que incluía el Cauca, Esmeraldas (Ecuador) y el Istmo. ${ }^{44}$ Ese argumento racista y paternalista, como lo llama Dumas para el contexto británico, no solo enfatizaba el temor a perder la fuerza de trabajo que podría utilizarse para desarrollar los proyectos económicos en el Pacífico. También reflejaba un ansia de control de estas poblaciones, la tensión que se derivaba del hecho de que la esclavitud era también una manera de estructurar el poder social. Una vez que este sistema se modificara con el fin de la esclavitud, la clase esclavista perdería su posición privilegiada en el orden social, con resultados funestos. ${ }^{45}$

La República de Colombia sufrió una crisis irreversible y las tensiones regionales entre Venezuela, Ecuador y la Nueva Granada precipitaron su disolución en 1830. La reestructuración de la Nueva Granada como república independiente agudizó conflictos internos, entre los cuales sobresale la cruenta lucha entre Bogotá y Popayán alrededor del mismo eje -el problema de la esclavitud- durante la primera guerra civil entre 1839 y 1842, llamada "Guerra de los Supremos". La polarización entre las élites de los bandos que se enfrentaron tomó visos sociales. Como sucedió en la guerra de independencia, en el Cauca hubo amplia participación de gente libre y esclavizada en los ejércitos, bajo el liderazgo de José María Obando. ${ }^{46}$ Esta estrategia de movilización militar fue percibida por los sectores conservadores

${ }^{44}$ Mosquera, Memoria, pp. 1, 10-12, 19.

${ }^{45}$ Dumas, Proslavery Britain. Esta visión que ataba la esclavitud al orden social es similar a lo que encontró Genovese para el caso del sur de Estados Unidos en las mismas décadas. Véase Genovese, The Slaveholders' Dilemma, pp. 13, $20,34$.

${ }_{46}$ El periódico El Ariete publicó el reporte de Ramón Mercado, que en 1841 Obando "puso en rebelión a los esclavos dándoles libertad, y después de un saqueo casi general de dichas haciendas y desmoralización de las cuadrillas de esclavos, consiguió reunir más de 800 hombres, la mayor parte negros esclavos". Ramón Mercado, "Variedades. Lo que va de ayer i hoy", El Ariete, Cali (3 ago. 1850). Díaz, Salteadores y cuadrillas de malhechores; Prado 
como una verdadera afrenta a sus privilegios, porque Obando ofreció la libertad a quienes se unieran a él. Decretó Obando en 1841: "son libres todos los esclavos de la provincia de Popayán que se hubiesen presentado al servicio de las armas, y los que en adelante se presenten". ${ }^{47}$ A raíz de esto, la movilización de la gente afrodescendiente se aceleró incluso más allá de Popayán y Buenaventura, en las provincias del Chocó, al norte. Por ejemplo, en abril de 1841, Sinforoso Paz reportó que en Celandia (Chocó) “muchos hombres malvados ... [habían formado] tertulias en que todavía tienen esperanzas". Paz estaba intentando convencer a los esclavos de que volvieran a las haciendas "imponiendo a los negros que no hay tal libertad que esto es un bochinche que sino [sic] trabajan el castigo elevará". ${ }^{48}$ En noviembre del mismo año, varios hombres fueron llevados a Buga a ser interrogados por el asesinato del gobernador del Chocó y uno de ellos, Agustín Gil, declaró que entre los revolucionarios a favor de Obando "se presentaron como cuatrocientos hombres, negros casi todos, y que blancos solo había como seis”. ${ }^{49}$

Después del final de la guerra, alrededor de las ciudades de Cali y Popayán, algunas comunidades de afrodescendientes libres y los esclavos de haciendas y minas siguieron ejerciendo violencia contra sus amos y difundiendo temor entre los esclavistas. ${ }^{50}$ Los esclavistas denunciaron desesperadamente esos desórdenes entre las poblaciones afrodescendientes y pidieron auxilio del gobierno central para controlarlas. El principal activista en este caso fue Julio Arboleda (de la familia

Arellano, Rebeliones en la provincia; Valencia Llano, Dentro de la ley, fuera de la ley, pp. 92-93.

${ }_{47}$ Decreto de 20 de abril de 1841, Artículo 1, en Gaceta del Canca, núm. 1, Popayán (21 abr. 1841), p. 2.

48 ACC, AM, 1841, paquete 33, leg. 62.

49 ACC, Rep. JC, 1841, c. 10. Sig. 8666.

50 Véase el periódico El payanés, que durante el año 1843 publicó noticias sobre "nuevos atentados que recientemente se han cometido en esta parte de la Nueva Granada” (núm. 20) y “sublevaciones de esclavos” (núm. 21). 
Mosquera-Arboleda), quien fundó el periódico El Payanés con el fin de hacer públicos los actos violentos de las poblaciones afrodescendientes y de esa manera justificar la necesidad de castigarlas y de legalizar su exportación.

Como ha demostrado María Camila Díaz Casas, esta fue una relación dialéctica entre las acciones violentas de los afrodescendientes, por un lado, y las solicitudes y la presión que ejercieron los esclavistas, por el otro. Lo segundo incluyó, aparte de la campaña de Arboleda en la prensa, un memorial que presentaron los esclavistas de las provincias de Buenaventura, Chocó, Pasto y Popayán a la Cámara de Representantes en Bogotá, diciendo:

Las provincias [...] constituyen una parte integrante muy principal de la Nueva Granada y no pueden perecer sin que la nación sufra la misma suerte [...] Los capitales que daban vida al comercio, y a la agricultura, a la minería y a todas las empresas productivas en estas provincias se fundaban en los capitales en esclavos que extinguió la ley sin compensación [...] Por esta extinción de capitales desaparecen también con todas las empresas productivas, los establecimientos de educación, los hospitales, las obras piadosas y fundaciones para el culto, las dotes y cuanto estaba fundado en esclavos.

El memorial también proponía medidas que veían como necesarias para poner un alto a los desórdenes en el Sur. Estas incluían dar protección a los esclavistas que quisieran exportar a los esclavos sediciosos y, complementariamente, derogar la prohibición del tráfico de esclavos. ${ }^{51}$

Estas estrategias de los esclavistas del Suroccidente neogranadino dieron lugar en 1842 a concesiones de parte del presidente Pedro Alcántara Herrán. El proceso tomó dos rumbos, los

51 "Memorial que los vecinos de Popayán enviaron a la cámara de representantes," en Posada y Restrepo Canal, La libertad de los esclavos en Colombia, pp. 3-14. Díaz, Salteadores y cuadrillas de malhechores. Rugemer, "The Development of Mastery and Race". 
mismos que Arboleda buscaba con su activismo en El Payanés. Primero, la criminalización de las acciones de estas poblaciones. Segundo, los dueños de esclavos consiguieron que el gobierno les permitiera exportar a los esclavos que representaban un peligro para el orden social. Así, estaban materializando en la legislación su imaginario sobre ese orden social y los mecanismos para preservarlo. Además, ese éxito se basó en su visión, que tenían el derecho de defender la riqueza que poseían en esclavos, desde la cual habían tradicionalmente manifestado su desacuerdo con el plan del gobierno en la ley de 1821 de usurparles su capital.

Como veremos a continuación, en la lucha de intereses entre las élites payanesas y aquellas que controlaban el gobierno en Bogotá se mezclaron variables que desbordaban los procesos regionales. Por una parte, los proyectos de desarrollo económico de la Nueva Granada que se articulaban con intereses transnacionales, con el Perú, Estados Unidos y Gran Bretaña, en este caso. Por otra parte, el poder económico efectivo de las élites del Suroccidente era estratégico para forjar las alianzas que harían viables esos proyectos. El momento en el cual el gobierno central concedió a los esclavistas su derecho a exportar los esclavos para recuperar su capital, entonces, nos habla a la vez de la relación entre la esclavitud y la formación del Estado, además de cómo ese proceso de formación del Estado tenía dimensiones internacionales. De la misma manera, la abolición de la esclavitud caracterizó los proyectos republicanos latinoamericanos no solamente como procesos nacionales; también implicó un flujo de ideas, capitales y personas en el Pacífico, tanto legal como ilegal.

\section{DIPLOMACIA, CIUDADANÍA Y EXPORTACIÓN DE ESCLAVOS \\ EN LA NUEVA GRANADA}

Los argumentos a favor de la reapertura del tráfico comenzaron a circular desde pocos años después de la publicación de la ley de abolición de 1821. Por ejemplo, en la correspondencia de 
la familia Mosquera vemos que el patriarca de la familia, José María Mosquera, padre de Tomás Cipriano y de Joaquín, le escribió a Gerónimo Torres en marzo de 1823 manifestando su alegría por la presentación que Torres hizo en el Congreso. Lo felicitó y expresó su gratitud. También le pidió que le mandara "25 o más ejemplares [de las Observaciones] para enviarlos a Quito a que se vendan y no dejaré de mandar algunos a Lima porque es conveniente que otros gobiernos adquieran conocimiento de lo que se ha reflexionado por acá”. Es decir, que J. M. Mosquera creía que sería muy importante informar a los dueños de esclavos en Quito y Lima acerca de las protestas que ellos en Popayán habían emprendido para que de esa manera "en esta parte se uniforme la opinión y ver cómo se evita nuestra ruina y el desorden que se prepara". En una carta que escribió en abril a José María Cárdenas, J. M. Mosquera le comentó que tenía mucha fe en la influencia de Torres en Bogotá. Sin embargo, añadió que sería importante sumar un punto a la propuesta de Torres: "concediendo extracciones a provincias extrañas, incluyendo en estas a los perjudiciales y levantiscos, que no son pocos". ${ }^{52}$

Esta cláusula justamente estaba presente en el proyecto de ley que José Rafael Mosquera, sobrino de J. M. Mosquera y primo de Tomás Cipriano y Joaquín Mosquera, presentó al Congreso en la Nueva Granada en 1824: Proyecto de ley sobre manumisión de esclavos e indemnización a los amos. Este proyecto retomaba varios puntos de la ley de 1821, declarando inicialmente el apoyo al proyecto de abolir la esclavitud. En su introducción dice: "Que siendo una de las más benéficas y justas leyes de Colombia la de la libertad de los partos, manumisión y abolición del injusto tráfico de esclavos, debe ser de todos modos

52 “Correspondencia de Don José María Mosquera a Jerónimo Torres”, pp. 209-213. 
razonable". ${ }^{53} \mathrm{~J}$. R. Mosquera, en el artículo 34, se refería directamente al tema de la exportación de esclavos problemáticos: "que se extraigan de algunos departamentos los esclavos que se han manifestado turbulentos o contrarios a la causa de la república a pesar de los beneficios que ella les dispensa. Los intendentes permitirán y facilitarán a los amos la extracción de estos esclavos fuera de Colombia". ${ }^{54}$

Así pues, está claro que ya desde 1824 la élite esclavista de Popayán tenía interés en exportar sus esclavos. Este plan iba en contra de, y estaba truncado por, la ley de 1821 que prohibía el tráfico. Sin embargo, los esclavistas consideraban que ese era un ajuste necesario a la ley, acorde con su queja de que la manumisión atentaba contra su justa propiedad de esclavos. Su insistencia en ese punto, además, revelaba que la venta de esclavos era una estrategia para deshacerse de las poblaciones afrodescendientes que se consideraban una amenaza para el orden social que sancionaba la autoridad de los esclavistas como la clase poderosa de Popayán. Y, en este caso, no denunciaban a los esclavos sólo por su criminalidad; resaltaban su carácter de "enemigos a la república" que se derivaba de la participación de los esclavos de las minas del Pacífico y de las ciudades de Popayán y Cali en el bando realista en contra de sus amos que eran, en su mayoría, insurgentes durante la guerra de independencia contra España. Así que en las estrategias tempranas de los esclavistas de Popayán se combinaban intereses por proteger su capital y recuperar el valor de sus propiedades, tanto como ejercitar una medida radical de expulsión de los esclavos que éstos consideraban peligrosos..$^{55}$

${ }^{53}$ Mosquera, Proyecto de ley. J. R. Mosquera era primo de Joaquín, Manuel María y Tomás Cipriano. Véase ArboledA, Diccionario biográfico y genealógico del antigno departamento del Cauca.

${ }_{54}$ Mosquera, Proyecto de ley. Énfasis mío.

55 Castellanos, La abolición de la esclavitud en Popayán, cap. 5. 
Como se vio, las cartas de José Antonio Arroyo a T. C. de Mosquera en julio de 1825 indican que ya en ese entonces se estaban vendiendo esclavos que vivían en Esmeraldas por $\mathrm{Pa}$ namá. En este caso no está claro quiénes eran los compradores, pero gracias a esa evidencia sabemos que el tráfico tenía lugar ilegalmente. ${ }^{56}$ Además, los historiadores Jacques Aprile Gniset y León Helguera afirman que el tráfico ilegal por el puerto de Buenaventura se remontaba a los orígenes de la república. Aprile Gniset afirma que, "de 1826 hasta 1850, por lo menos, los negociantes neogranadinos o extranjeros, lo mismo que capitanes de barcos, incluso europeos [...] negociaban por igual con oro o esclavos" ${ }^{57}$ El lugar central de la propiedad en esclavos en estos negocios y el mercado local de ventas minoristas en Buenaventura sugieren que, a pesar de la existencia de una ley de abolición del tráfico de esclavos, se mantuvo el intercambio de los mismos, tanto en las localidades como a través del Pacífico.

Otra evidencia nos muestra que el tráfico se dio desde antes de su legalización en 1843 y que, en el puerto de Paita en el Perú, esclavos y sus hijos que habían nacido libres se importaban para trabajar como empleados domésticos y en las haciendas desde la década de 1830. Por ejemplo, en 1848, María Portocarrero, de Nueva Granada, se quejó en la corte de Paita diciendo que había sido introducida al Perú clandestinamente por Jacoba Távara en 1833. Sus hijas, Matea Torres (de 10 años) y Dolores

\footnotetext{
${ }^{56}$ José Antonio Arroyo a T. C. de Mosquera, Popayán, 12 de diciembre, 1825. ACC, SM, 1,610. "No puede Usted imaginar los esfuerzos que hice en Quito y en Ecuador para la reducción de los esclavos que tenemos en crecido número en el río de Santiago [...] les hice propuestas locas pero nada fue admitido". Castellanos, La abolición de la esclavitud en Popayán, cap. 5. Sobre la crisis de la esclavitud en Esmeraldas durante la independencia, véase RuEda, "Territorio, movilización e identidad étnica”.

57 ApriLe GnISET, "El Cascajal, puerto republicano y negrero", cap. 8, cita en p. 100.
} 
Reina (de 6 años), habían ido a Piura con su madre porque ella no quería abandonarlas. ${ }^{58}$

La trata, o la expulsión de las personas caracterizadas como indeseables, dependía también del previo establecimiento de alianzas con inversionistas europeos en el Pacífico que durante estas décadas eran agentes cruciales para modernizar el proceso de extracción del oro con nuevas tecnologías. En esas negociaciones, los esclavistas ofrecían sus esclavos como fuente de fuerza de trabajo, y por lo tanto de ahorro, lo cual les permitía hacer ofertas atractivas a los europeos para atraer su capital. En junio de 1825, por ejemplo, decía en una carta Manuel Martínez a T. C. de Mosquera que las obras más difíciles y lucrativas iban a ser absorbidas por los capitalistas europeos que

[...] pretendían privilegios exclusivos para trabajar con ellas [...] Podremos resolver algo siempre contando con el recurso más efectivo con el servicio de los esclavos de la costa que tenemos en las minas [...] Consider[o] de grande importancia el provecho que darían los esclavos trabajadores, ahorrando costos inmensos. ${ }^{59}$

Es decir, los esclavos eran un elemento vital sobre la base del cual se desarrollaban los negocios de los esclavistas con miras a expandir la economía regional y nacional. ${ }^{60}$

58 AGNC, Consulados, Consulados Varios, t. 4, f. 516.

59 Manuel Martínez a T. C. de Mosquera, Bogotá, 6 de febrero, 1825. ACC, SM, 2,064. Énfasis mío. Martínez continúa diciendo: "En la capital ha llegado un inglés Dr. Roberto Marchall Key que tiene compañía emprendida con otro inglés y Rafael para poner máquinas de vapor u otras y sacar el oro de los cauces de los ríos y quebradas del Chocó y la Buenaventura [...] Cooperando con esclavos y es un argumento más de hecho que para el proyecto del camino lo haríamos casi todo con los de nuestras cuadrillas".

${ }^{60}$ Sobre el proyecto de desarrollo que primó en la Nueva Granada, y el papel de Tomás Cipriano de Mosquera en éste, ver, por ejemplo, el clásico de SAfFord, The Ideal of the Practical. Safford, sin embargo, no estudia la esclavitud ni el trabajo esclavo en ese proceso. 
Es interesante la diferencia entre la propuesta de Gerónimo Torres, que buscaba integrar a los libertos a la economía, y la que vemos en este caso, cuando los esclavistas estaban decididos a tomar medidas extremas, fundadas en su percepción de un antagonismo intrínseco a la relación entre su clase y la de los esclavos. A raíz de ese antagonismo, que se había materializado desde la independencia y luego en la Guerra de los Supremos, los esclavistas estaban dispuestos a perder mano de obra potencial para prevenir trastornos sociales.

Había otra relación entre el discurso de Torres en 1822 y el desarrollo de la trata legal por el Pacífico. Torres señaló un problema en el proyecto de otorgar el estatus de libertad a los hijos de esclavas nacidos después de 1821. Dijo que su lógica era perniciosa para las familias y las comunidades de esclavos y que la ley de libertad de vientres tenía un efecto desestabilizador, porque no era posible que los familiares de los niños que nacieran después de publicada la ley se quedaran tranquilos pensando que solamente una fracción de sus comunidades estaba accediendo a la libertad. Torres se refirió a esto en términos de una combinación de injusticia con envidia: “ ¿mis hijos son libres, dirán, y yo permaneceré eternamente esclavo?”. ${ }^{61}$ Sobre el mismo punto, en 1825, J. Mosquera citaba a George Canning, activista británico por la abolición, quien había dicho contra la ley de libertad de partos que "no hemos declarado libres a todos los nuevamente nacidos [...] [medida que] habría creado un celo mutuo entre los negros". 62

Así es que esta discusión sobre los efectos de la manumisión en las familias de esclavos constituye un precedente relevante de los hechos que tuvieron lugar entre 1843 y 1847 cuando se abrió

61 Torres, Observaciones, p. 22.

62 Mosquera, Memoria, p. 22. Desde el Foreign Office Canning estuvo directamente involucrado con América Latina durante el proceso de reconocimiento de las nuevas repúblicas. También en las negociaciones británicas para la supresión de la trata. 
la trata en la Nueva Granada. El caso de la controversia alrededor de la venta de esclavos a Perú que discutiré a continuación también revelaría que la idea de mantener a las familias unidas justificaba exportar a los hijos libres de las esclavas, llamados manumisos, junto con sus padres. Y esto se articulaba con la misma ley de 1821 que prohibía que se separasen los hijos libres de las esclavas de sus padres e igualmente los miembros de una pareja casada. Aunque se planteó en un tono humanitario, se relacionó con la estrategia de los esclavistas payaneses para buscar beneficios y evadir las normas de la Constitución de 1821.

Entender la exportación de esclavos por el Pacífico requiere que tengamos en cuenta los cambios en la geopolítica de la esclavitud en el Perú. Además, a nivel más general, la política a favor de la esclavitud en la Nueva Granada debe ponerse en una perspectiva más amplia, suramericana, para apreciar sus paralelos y relaciones con otros contextos. ${ }^{63}$ En el Perú, después de la independencia los hacendados emprendieron una lucha ideológica contra las medidas abolicionistas de Bolívar y San Martín, culpándolos del declive en la economía peruana. Durante la década de 1830 la presión por parte de los hacendados del norte se intensificó y dio frutos. Así como lo habían hecho los representantes de los dueños de esclavos de Popayán, los esclavistas en Perú desplegaron una campaña defendiendo la esclavitud. Su tarea defensiva se plasmó en un texto que reunió argumentos a favor de la esclavitud, titulado Reclamación de los vulnerados derechos de los hacendados (1833), escrito por el conservador José María Pando. ${ }^{64}$ Como en los textos de Gerónimo Torres y los miembros de la familia Mosquera, la Reclamación retomaba debates de largo alcance sobre el tema de la esclavitud y la aboli-

${ }^{63}$ La presión de la clase esclavista a los gobiernos republicanos de la primera mitad del siglo xix no fue exclusiva de la región andina. También en Argentina se reestableció el tráfico temporalmente. Véase ANDREws, The Afro-Argentines of Buenos Aires.

${ }^{64}$ Pando, Reclamación de los vulnerados derechos de los hacendados. 
ción en Hispanoamérica desde finales del siglo xviII, todo en un contexto atlántico. También, para sustentar sus argumentos, la Reclamación se refería a los casos específicos de Estados Unidos, Gran Bretaña, Haití, Guatemala y Colombia.

En el texto, Pando mencionaba a Estados Unidos para resaltar la compatibilidad de la esclavitud con el republicanismo. También reflexionaba sobre la manera en que otros estados habían lidiado con los retos de la abolición, como Gran Bretaña en relación con sus colonias en el Caribe. Esa última experiencia ilustraba la lógica de recompensar a los dueños de esclavos por su propiedad e igualmente la estrategia de control de las poblaciones emancipadas para el beneficio de las economías extractivas. Así mismo, mencionaba el caso de Haití, específicamente el código rural que diseñó el rey Henri Christophe en 1812 para regular el trabajo en las plantaciones. También citaban a J. Mosquera como referencia a Colombia, en especial sus denuncias de las conmociones del Chocó y Barbacoas y la manera en que los libertos "se hallan connaturalizados con la vida ociosa". 65

Estas referencias a los lugares donde la esclavitud había continuado o sufrido cambios son un indicador de la forma en que los esclavistas de las repúblicas suramericanas se mantenían informados de los experimentos con formas de trabajo que estaban teniendo lugar a lo largo y ancho del mundo atlántico. Parece paradójico que se interesaran en evocar los dos casos que en la historia del abolicionismo fueron paradigmas -Haití, donde se abolió la esclavitud durante la revolución, y Gran Bretaña, con su incansable campaña de abolición de la trata-y que por lo general se toman como ejemplo de radicalismo en el proceso del desmantelamiento de la esclavitud. Aunque uno de los más claros y difundidos impactos de la revolución haitiana

${ }^{65}$ Pando, Reclamación de los vulnerados derechos de los hacendados, pp. 16, 21-22. 
en las sociedades esclavistas fue el miedo, a tres décadas de la revolución, para los esclavistas del Pacífico suramericano Haití había pasado a representar un arquetipo en el cual se había recuperado la capacidad de control sobre los trabajadores por parte del gobierno y la legitimidad de tomar medidas para hacerlo con el fin de proteger las economías nacionales.

Así como en 1833 Pando demostró estar informado sobre la lucha de los esclavistas payaneses en Colombia al citar el memorial de J. Mosquera, en las cartas que circularon entre los miembros de la familia Mosquera en Popayán en 1838 vemos referencias similares a Haití y Gran Bretaña como las que aparecieron en Reclamación de los vulnerados derechos de los hacendados. Es decir, parece muy posible que fuera por medio de la lectura de este texto publicado en Perú que los esclavistas de Popayán incorporaron en su repertorio la idea de modelar los sistemas de control laboral de los libertos en los precedentes haitiano y jamaiquino. Esto es un punto más que revela la existencia de alianzas ideológicas entre los dueños de esclavos -como clase transnacional-alrededor de intereses comunes en validar su propiedad en esclavos. ${ }^{66}$

Así mismo, si bien desde proyectos económicos diferentes -en el Perú, la proyección era sobre la economía agraria de plantaciones y, en la Nueva Granada, Popayán aún contaba con un sector minero fuerte-, los procesos económicos, sociales y políticos de los dos países convergieron durante las décadas de 1830 y 1840. La convergencia económica de la Nueva Granada y el Perú se dio además a nivel del desarrollo de un proyecto de transformación a las leyes antiesclavitud establecidas en las constituciones fundadoras de las repúblicas.

Con la llegada de Felipe Santiago de Salaverry en 1835 al gobierno de Perú, comenzó la coyuntura en la que los esclavistas lograron conseguir concesiones a su favor. En 1839 fue Agustín

66 Marquese, Parron y Berbel, Slavery and Politics. 
Gamarra, aliado de los esclavistas, quien facilitó la legalización de la importación de esclavos al Perú y esa ley se articuló con el proyecto económico peruano de expansión de las plantaciones de azúcar en el norte. Con sus campañas legislativas, desde la Constitución de 1839 sus esfuerzos culminaron en la aprobación de la ley de julio 29 de 1845 que permitía la importación de esclavos. Mientras tanto, como hemos visto, en la Nueva Granada la tensión social que se intensificó con las luchas regionales durante la Guerra de los Supremos (1839-1842) dio pie al fortalecimiento de las élites esclavistas, que resultó en su éxito para, de manera paralela, cambiar las leyes y permitir la exportación de esclavos. ${ }^{67}$

En ese contexto, Julio Arboleda escribió a T. C. de Mosquera:

Mi querido tío y amigo [...] En el Perú hay actualmente un buen mercado para los esclavos. Los propietarios granadinos están, pues, en situación de deshacerse de un cáncer, y de traer un verdadero capital al país [...] ¿Deben las autoridades del orden público restringir o favorecer la exportación? [...] Bien comprendo yo que la propia delicadeza y el santo temor de la opinión pública no le permitirá a Usted derogar aquel maldito decreto a pesar de sus convicciones. Sin embargo, ¿no podrá reformarse? ¿No podrá recomendarse a las autoridades del orden político que sean tolerantes en esta materia sin necesidad de un acto que aparezca en la gaceta?68

Esta evidencia de la existencia de un mercado de esclavos en el Pacífico reitera la existencia de una red de exportación de esclavos por el puerto de Cascajal en Buenaventura que, como hemos visto, ya tenía lugar desde mucho antes de su legalización en

67 Blanchard, Slavery and Abolition in Early Republican Peru, esp. cap. 3; Gootenberg, Between Silver and Guano, p. 75; Kitchens y Helguera, "Los vecinos de Popayán y la esclavitud en la Nueva Granada".

68 Julio Arboleda a T. C. de Mosquera, Popayán, 9 d agosto de 1846. ACC, SM, 20,672. DíAz, Salteadores y cuadrillas de malhechores, p. 269. 
1843 y se mantuvo hasta después de que se reinstauró la prohibición de exportaciones de esclavos fuera de la Nueva Granada. Por ejemplo, en 1847 el cónsul de Lima reportó que un buque se dirigía a Buenaventura y se sospechaba que justamente estaba involucrado en la trata de esclavos. ${ }^{69} \mathrm{Y}$ fue en Buenaventura donde se inició la más famosa transacción, en abril de 1847, que generó una controversia internacional con Gran Bretaña. Se trata de la venta que hizo el mismo Julio Arboleda de un total de 212 personas. Estos se trasladaron primero a Panamá, desde donde se embarcaron hacia el puerto de Paita en el Perú. Sin embargo, en ese grupo había solamente 53 esclavos y el resto eran manumisos. La venta de los manumisos se sustentó en el argumento de que la ley no permitía que se separasen las mujeres de sus hijos y que debían mantenerse unidas las familias. Pero, claramente, se trató de una violación a la ley de libertad de vientres que no solamente había declarado libres a los hijos de esclavas nacidos después de 1821, sino que además prohibía expresamente que éstos se vendieran. ${ }^{70}$ Veremos a continuación cuál fue la discusión que se dio a raíz de esas tensiones y contradicciones, en particular frente a los diplomáticos británicos que las denunciaron.

La exportación de manumisos hacia el Perú visibilizó en la arena internacional las inconsistencias que implicaba haber legalizado el tráfico de esclavos en ambos países. El cónsul británico en Bogotá, Florencio O’Leary, reaccionó inmediatamente para

\footnotetext{
69 AGNC, Consulados, Consulados Varios, t. 4, ff. 327.

70 Arboleda Llorente, "Venta de esclavos en Popayán", p. 164. Aprile GNISET, "El Cascajal, puerto republicano y negrero", p. 109, dice que fueron "272 individuos de ambos sexos, desde un bebé de un año y cuatro meses hasta ancianos de sesenta años. Se registran 49 familias completas, seguidas por dos parejas sin hijos, terminando el listado con 25 solteros y solteras. Se omite decir que acompañan estos llamados solteros un cónynge libre, por su voluntad, el cual no figura ni en la venta ni en el precio; pero sí será embarcado, deportado y probablemente vendido". Desafortunadamente Aprile Gniset no revela sus fuentes.
} 
denunciar ese paso que chocaba con la política abolicionista neogranadina, y la que primaba en América y Europa. O’Leary tenía la siguiente información:

The Peruvian 'Tres Amigos' had arrived at the port of Panama for the purpose of embarking there, and conveying to Peru, a considerable number of slaves, natives of New Granada, which slaves had been sold by Mr. Juan Fernand to Mr. Rodulfo [...] Among the slaves were many young persons legally entitled to their freedom on attaining the age of eighteen. ${ }^{71}$

Y su argumento era que el tráfico violaba los términos del tratado de 1825 entre Colombia y Gran Bretaña, específicamente el artículo 13 del mismo, que prohibía a todas las personas residentes dentro del territorio neogranadino tomar parte en el tráfico de esclavos.

Esta controversia demuestra varias cosas. Primero, que cuando analizamos la resistencia que hubo en el mundo atlántico a las políticas británicas en contra de la trata de esclavos, no sólo Cuba o Brasil manejaron una doble agenda. Es bien conocido el tipo de maniobras tanto de España como de Brasil para mantener el tráfico desde África y expandir sus economías esclavistas durante el siglo xix, a pesar de haber concedido tratados con Inglaterra para frenar el tráfico transatlántico. ${ }^{72} \mathrm{El}$ tipo de comercio de esclavos -y, peor aún, de libertos- que se desarrolló en el Pacífico en las décadas de 1830 y 1840, en este caso entre la Nueva Granada y el Perú, era una afrenta directa a

${ }^{71}$ Kitchens y Kitchens, "La exportación de esclavos neogranadinos”, p. 258. Énfasis mío.

72 Véanse Berquist, "Early Antislavery Sentiment in the Spanish Atlantic World"; Bethell, The Abolition of the Brazilian Slave Trade; Ferrer, Freedom's Mirror; Fradera y SCHMIDT-Nowara (coords.), Slavery and Antislavery in Spain's Atlantic Empire; Marquese, Parron y Berbel, Slavery and Politics. 
esos compromisos que estas repúblicas también se proclamaban interesadas en defender. Lo interesante es la manera en que los políticos neogranadinos justificaron esa decisión de cambiar sus leyes en el sentido contrario. Porque, a diferencia de los casos de Cuba y Brasil, al hacerse legalmente, la decisión de la Nueva Granada de permitir la exportación de esclavos fuera de su territorio tuvo que ser defendida en la arena internacional.

Pedro Fernández Madrid, representando la Secretaría de Relaciones Exteriores, intentó defender la medida diciendo, primero, que "por lo que hace a los que se venden en el interior, la práctica contraria se ha seguido constantemente, sin reparo ni objeción por el gobierno británico” y dijo que la exportación de esclavos hacia el Perú contribuía “directamente a la rápida extinción de la esclavitud en la Nueva Granada, pues es claro que disminuyéndose por la exportación el número de esclavos que existen en la Nueva Granada más pronto podrán manumitirse los que en ella queden". ${ }^{33}$ Aquí, nuevamente, vemos el papel importante que jugaba la noción de frontera en estas negociaciones, que permitía a los neogranadinos ver la venta de esclavos hacia fuera de la Nueva Granada como un paso positivo en el camino a la abolición, idea que O’Leary refutó poniendo el proyecto abolicionista en un plano más amplio, transnacional, diciendo que el razonamiento de Fernández Madrid era absurdo porque ese comercio aumentaba la esclavitud en el Perú. Es decir, O’Leary resaltó la manera en que la esclavitud y su abolición en el hemisferio debían verse en conjunto y no como hechos atados únicamente a los contextos nacionales.

Por otra parte, un argumento que puso un alto a las presiones británicas fue el de la soberanía. Según los neogranadinos la intromisión representaba una afrenta a la soberanía neogranadina, por lo cual perdía legitimidad. Estratégicamente este

73 Véase Kitchens y Kitchens, “La exportación de esclavos neogranadinos", p. 263. 
punto tuvo mayor efectividad y O’Leary se retractó frente a esa queja diciendo "there was no intention on the part of the British negotiators to interfere with [the rights of property] in New Granada”. Sin embargo, también añadió un punto clave, el más serio en esta confrontación: que aunque la estrategia de los esclavistas del Cauca se basaba en la cláusula aparentemente filantrópica de que "la venta de esclavos se haga sin dividir matrimonios”, al mismo tiempo se estaba violando la condición de que "los hijos de esclavos nacidos libres a virtud de la ley no se extraigan con motivo de pretexto alguno". ${ }^{74}$

Un punto igualmente relevante del intercambio entre el cónsul británico y los legisladores neogranadinos es que O’Leary incorporó el cristianismo como una razón por la cual la venta de esclavos hacia Perú en realidad era gravemente problemática. Este planteamiento buscaba refutar a los neogranadinos que querían justificarlo diferenciándolo del tráfico transatlántico desde África.

Reestablishing a traffic in slaves more unrighteous than that which the great majority of the powers of Christendom have combined to suppress in as much as the victims of the new system are not poor benighted savages of Africa but natives of New Granada and Christians ... [a trade] inconsistent with the free institutions of the republic and manifestly at variance with its international engagements. ${ }^{75}$

Es decir, que en el contexto del debate diplomático se plantearon tanto el tema de la calidad de los manumisos nacidos en Nueva Granada como la otra dimensión local, de la ciudadanía, que también resonaba como un argumento de peso en el conflicto internacional, por revelar una inconsistencia con

74 Kitchens y Kitchens, “La exportación de esclavos neogranadinos”, pp. 264, 277. Enfasis en el original.

75 Kitchens y Kitchens, “La exportación de esclavos neogranadinos”, p. 259. Enfasis mío. 
los principios republicanos. Este punto de O'Leary por una parte deja ver que aún en la década de 1840 se consideraba a un africano "salvaje sustancialmente diferente" de un afrodescendiente nacido en la Nueva Granada, por suponerse este último cristiano. A pesar de que revela una inconsistencia en el discurso británico en contra de la trata africana, de esa manera O'Leary añadió un punto definitivo al argumento de la incompatibilidad del tráfico internacional en el Pacífico con los compromisos diplomáticos de la Nueva Granada. Lo más interesante aquí fue su denuncia de la violación de un principio básico republicano, de proteger los derechos de sus ciudadanos.

Las élites de Popayán estaban involucradas en manejar el tema diplomático y el Estado neogranadino hizo un gran esfuerzo por maniobrar frente a la oposición británica a la reapertura del tráfico. No es sorprendente, en este sentido, que T. C. de Mosquera fuera el presidente de la Nueva Granada en ese mismo momento. Él, finalmente, tenía claro su deber de defender el derecho de los payaneses a vender sus esclavos. Estos vínculos los muestra la carta de Joaquín Mosquera a T. C. de Mosquera en noviembre de 1846 en que le decía:

No he tenido aptitud para ocuparme de meditar el artículo del tratado inglés por darte mi opinión sobre la protesta de O’Leary contra la exportación de esclavos para el Perú.

Recuerdo que el señor Gual presentó en el senado el protocolo de conferencias sobre aquel tratado para conocer si las estipulaciones de aquel artículo son absolutamente generales o solo se contrae al tráfico de esclavos de África. ${ }^{76}$

Es importante, pues, que esta serie de choques en las relaciones diplomáticas tuvieron eco dentro de la Nueva Granada

${ }^{76}$ Joaquín Mosquera a T. C. de Mosquera, Popayán, 4 de noviembre, 1846. ACC, SM, 21, 728. 
en la siguiente década en la política local entre conservadores y liberales. Los primeros continuaban defendiendo la esclavitud y sus corolarios, la venta de esclavos y la disciplina laboral entre los afrodescendientes libres, aclarando que, como dueños de esclavos, "tenemos religión, piedad y podemos ser buenos cristianos". Además, citaron a las naciones ilustradas, como Estados Unidos, "que tiene más de un millón de esclavos" y a las repúblicas de México, Perú, Chile y Buenos Aires "que, respetando el derecho de propiedad sobre los esclavos, no han seguido el ruinoso y precipitado ejemplo de los legisladores colombianos que declararon la libertad de partos sin ninguna indemnización”. Hasta ahora los historiadores han afirmado que en el contexto republicano se había silenciado absolutamente la posibilidad de argumentar a favor de la defensa de la esclavitud. Sin embargo, es notorio que esta proclama de 1846 de los esclavistas en Cali planteó un apoyo explícito, transparente, a la institución de la esclavitud. ${ }^{77}$

Los liberales, autoproclamados "republicanos", en cambio, estaban en defensa de la abolición, y, sobre todo, denunciaban lo que llamaron "contrabando de carne humana". Vale la pena desglosar la posición de los republicanos, que no estaba exenta de un trasfondo racista. Por un lado, criticaban la venta de los manumisos como inhumana pues al traspasar la frontera de la Nueva Granada hacia el Perú, los libertos perderían la garantía de su libertad: "En el Perú se proponen vender la servidumbre del liberto de por vida". Pero también pensaban que la exportación de esclavos y manumisos era una amenaza a la economía neogranadina.

Prescindiendo de que las razones de utilidad y conveniencia que aducen los peruanos para apoyar la introducción de esclavos en su

77 "La esclavitud está apoyada en los libros sagrados". Citaron Éxodo, cap. 21 y San Pablo en su carta a los de Éfeso, cap. 6. Énfasis mío. 
tierra, pueden alegarse por nosotros con mucha más fuerza para que no se permita la extracción de ellos porque aparte de que nuestra minería y agricultura carecen de los brazos necesarios y nuestras costas del Chocó solo pueden ser pobladas por la raza africana, tiene esta cuestión otros puntos graves de trascendencia considerada bajo el aspecto de la moral y de los principios sociales [...] con quienes se quiere traficar como si fueran bestias o seres inanimados cuando son nuestros semejantes y quizá la porción más productiva de nuestra población. ${ }^{78}$

Los liberales, entonces, no acompañaron sus críticas de una posición meramente humanitaria. Más bien buscaron competir con los hacendados peruanos usando una lógica económica, señalando que si se cedía la mano de obra al Perú la Nueva Granada perdería la posibilidad de aprovechar productivamente la región pacífica. Para este grupo progresista, entonces, el argumento en contra de la trata no pasaba por el tema de la ciudadanía sino de la fuerza de trabajo que representaban los afrodescendientes.

Pedro Gual, diplomático con mucha experiencia de negociación con la Gran Bretaña desde el periodo colombiano, planteó su oposición a la exportación enfocándose en demostrar que era un punto muy sensible en el ámbito de las relaciones internacionales. Así, al final, los legisladores en la Nueva Granada resolvieron volver a abolir la trata en 1847 . En junio de 1847, el secretario de Relaciones Exteriores de la Nueva Granada, Mallarino, comunicó a Manuel María Mosquera que en la $G a-$ ceta número 874 del 28 de abril del mismo año apareció la ley derogando los artículos de la ley de 1843 y que, "por tanto, la importación como la exportación de esclavos han quedado

78 Anónimo, "Unos republicanos". Contrabando de carne bumana. BNC, $P$, 803, F.710. Énfasis mío. 
absolutamente prohibidas”, y pedía a Mosquera que le comunicara aquello a Lord Palmerston para resolver el problema. ${ }^{79}$

Años más tarde, sin embargo, el impacto de la exportación ilegal de manumisos continuaba causando problemas diplomáticos. Después de la abolición definitiva de la esclavitud en la Nueva Granada en 1852, el cónsul neogranadino en Perú, Manuel Ancízar, se embarcó en un esfuerzo por reintegrar a los manumisos que habían sido exportados ilegalmente. Todavía en 1855 continuaba su proceso de repatriación. ${ }^{80} \mathrm{Y}$, en los años posteriores a 1847, en Perú se reportaron varios casos de afrodescendientes que denunciaron en la corte, evidentemente en conexión con el cambio de ley en la Nueva Granada, el hecho de haber sido vendidos ilegalmente, siendo libres, como esclavos en el Perú. Tal fue el caso de Cristóbal Lozano, quien en 1849 se presentó frente al cónsul neogranadino L. Pardo pidiendo justicia, diciendo que lo habían vendido en el Perú viniendo desde la Nueva Granada, aunque era libre. ${ }^{81}$

Pero, paradójicamente, a comienzos de la década de 1850, las ventas de esclavos de los esclavistas payaneses continuaron. Esto justo en la víspera de la abolición de la esclavitud, cuando en la Nueva Granada se estaban adelantando medidas liberales en varios niveles, después del triunfo definitivo de los valores antiesclavistas y republicanos. Esta vez los esclavistas se organizaron bajo el liderazgo del entonces expresidente T. C. de Mosquera para transportar los esclavos a Panamá. Es decir, en este momento T. C. de Mosquera estaba cumpliendo los

79 Kitchens y Kitchens, “La exportación de esclavos neogranadinos”, pp. 290-291.

80 ACHUN, $M A B, C O$, Repatriación de Esclavos 1852-1856. Helguera, "La exportación de esclavos en la Nueva Granada”, p. 459. Otros casos en los juzgados locales de Paita revelan la problemática alrededor del estatus de los manumisos importados de la Nueva Granada.

81 AGNC, Consulados, Consulados Varios, t. 4, ff. 107-108. Véase también AP, $C C, E R$, Juzgado de primera instancia, c. 69, exp. 1377, 17 de octubre, 1846; c. 69, exp. 1356, 12 de julio, 1846; c. 75, exp. 1510, 14 de junio, 1848. 
deseos que Julio Arboleda le manifestó tres años antes. La nota que envió Vicente Javier Arboleda (quien había tenido cargos políticos tanto a nivel nacional como dentro de la gobernación de Popayán) a T. C. de Mosquera en enero de 1850 da cuenta del liderazgo de T. C. de Mosquera: "En el momento distribuí tu carta a todos los propietarios de esclavos y me parece que muchos convendrán". ${ }^{82}$

Estos planes no constituían una afrenta explícita a la legislación contra el tráfico que, como ya dije, se había reinstituido en 1847. Más bien, en este momento los esclavistas aprovecharon que Panamá era parte de la Nueva Granada y la transferencia de los esclavos estaba dentro de la ley. Pero en Panamá, con T. C. de Mosquera como intermediario, los esclavistas estaban negociando la venta de esclavos con la compañía estadounidense Panama Railroad Company (PRC), que estaba construyendo el ferrocarril. Este proyecto se contrató durante el gobierno de T. C. de Mosquera. Es más, él era activista en la compañía y se relacionó para la venta de los esclavos especialmente con John L. Stephens, uno de los inversionistas en Nueva York.

Es así que a comienzos de la década de 1850 en Panamá se dio forma a una colaboración entre la compañía de construcción del ferrocarril y los esclavistas neogranadinos -principalmente payaneses- que veían una oportunidad de recuperar sus capitales con esas ventas. T. C. de Mosquera, como socio de la misma, representó los intereses de la clase de dueños de esclavos en estas negociaciones. Las cartas y otros documentos de la familia Mosquera que registran aquellas transacciones dejan ver que los esclavistas de Popayán todavía veían a sus esclavos como fuente primordial de su riqueza. Que estos negocios se dieran justo antes de la abolición definitiva demuestra la intención estratégica de los esclavistas de maniobrar frente a las limitaciones

82 Vicente Javier Arboleda a T. C. de Mosquera, Popayán, 16 de enero, 1850. ACC, SM, 27,339. 
definitivas que el Estado intentaba establecer anunciando la emancipación final. ${ }^{83}$

El mismo V. J. Arboleda escribió a T. C. de Mosquera en febrero del año 1850 para comunicarle que él y sus hermanos tenían para la venta unos 135 esclavos en las minas de Viroviro y Tajuato con 125 manumitidos, explicando cómo calculaba sus precios:

Acompaño a Ud la lista de los esclavos y manumitidos que en compañía de mis hermanos Joaquin y Vicenta tenemos en la provincia del Chocó en las minas de Viroviro y Tajuato. Hay en ambas minas ciento treinta y cinco esclavos y ciento veinticinco manumitidos. Los vendemos todos los esclavos sin excepción ninguno por la dificultad de arreglar los que queden y para que la compañía que los compra pueda sin perjuicio tomarlos todos. Rebajaremos en el valor de los alimentos de manumitidos la cantidad que importen los esclavos que no sean utiles para el comprador. El valor de los manumitidos es a razón de diez pesos anuales; calculando hasta los diez años a diez por rebajado los dos primeros años y los que tengan más de diez años a diez pesos anuales por cada año que les falte para cumplir los diez y ocho señalados por la ley. ${ }^{84}$

Esto sugiere que los propietarios de esclavos en Popayán no habían acatado la prohibición del tráfico, ni consideraban que la venta de manumisos fuera problemática, es decir, que tuviera una lógica contraria a la ley de libertad de vientres. Para éstos,

83 Véase ACC, SM, carp. 50 (Varios), 1861. También, Vicente Javier Arboleda a T. C. de Mosquera, Popayán, 5 de febrero, 1850. ACC, SM, 27,341: "Hoy te contesto sobre el negocio de los esclavos mandan doce listas algunos esclavos y lo mismo manumitidos hay sin edades porque no he podido ponérselas por carecer de datos. En mi carta expreso las bases del contrato, tú me dirás luego que conferencias con Estephens lo que te parezca".

${ }_{84}$ Vicente Javier Arboleda a T. C. de Mosquera, Popayán, 4 de febrero, 1850. ACC, SM, 27,340. Énfasis mío. 
por el contrario, se trataba de recuperar su inversión en la manutención de los manumisos y el valor de los mismos jugaba un papel central en su negociación de los precios de los esclavos, todos ellos vistos en conjunto.

En una versión de borrador del contrato entre los esclavistas de Popayán y la Panama Railroad Company (PRC), fechado en marzo de 1850, T. C. de Mosquera aparece como el apoderado de la PRC en Nueva Granada, con el poder que le confirió Stephens, agente de la PRC en Nueva Granada, para llevar a cabo la venta de los esclavos de Vicente Javier, Manuel Esteban, Manuel Antonio e Ignacio Arboleda, además del Dr. Jaime Arroyo, con el fin de "abrir el camino de fierro en el Istmo de Panamá". Los tres primeros puntos del contrato son interesantes de resaltar:

1. La compañía pagará los esclavos casados a razón de 375 pesos marido y mujer y los varones solteros a razón de 200 pesos siempre que tengan las condiciones que se expresan en el número siguiente.

2. Los esclavos deben ser sanos y robustos, adecuados para el trabajo al cual se les destina, no debiendo padecer ninguna enfermedad crónica ni contagiosa ni ser mayores de 48 años de edad.

3. La compañía se obliga a pagar a los vendedores los servicios que están obligados a prestar los hijos de estos esclavos conforme a la ley hasta la edad de 15 años [...] pero se advierte que si según este arreglo algún manumiso vale más de 70 pesos, la compañía no pagará sino esta suma, pues la cantidad de 70 pesos es el máximo. ${ }^{85}$

Estos términos sugieren que la venta de esclavos estuvo dirigida a promover el trabajo en el ferrocarril a favor de la inversión

${ }^{85}$ Castrillón, Tomás Cipriano de Mosquera, p. 375. ACC, SM, 28, 263. 
estadounidense. A todas luces, y a pesar del amplio activismo contra la esclavitud en ese entonces, tanto en Nueva Granada como en los contextos más amplios hemisférico y atlántico, la esclavitud era una institución que sustentaba los negocios entre las partes y el proyecto de desarrollo. Como lo demuestra el punto tercero, por otro lado, también se consideraba legal y viable vender a los manumisos, es decir, jóvenes que habían nacido libres bajo la ley de 1821, aun cuando se reconocía tangencialmente su potencial liberación a los 15 años.

En Panamá, según Aims McGuinness, la PRC, poco después de que tuvieron lugar estas negociaciones, dejó de utilizar trabajo esclavo y comenzó a importar indentured workers, algunos de Cartagena y otros de Jamaica, Estados Unidos y China. ${ }^{86} \mathrm{Sin}$ embargo, está claro que el activismo de T. C. de Mosquera a favor de los esclavistas en 1850 promovió sus intereses como dueño de esclavos e inversionista en el ferrocarril, al mismo tiempo que lideró uno de los más importantes proyectos de desarrollo de Estados Unidos en territorio neogranadino. Al trasladar a los esclavos de Popayán y venderlos a la PRC, Mosquera contribuyó al proceso de expansión del poder de Estados Unidos en el hemisferio. Y el compromiso de Mosquera de defender los intereses de su propia clase se hizo evidente justo cuando el nuevo presidente liberal, José Hilario López, abolió la esclavitud en Nueva Granada el 21 de marzo de 1851. El 26 de junio de 1851 Mosquera y sus aliados esclavistas de Popayán escribieron una carta protestando la decisión de López. Estas tensiones nuevamente resultaron en una confrontación militar en la cual los conservadores de Popayán se opusieron a las medidas liberales de López, principalmente la abolición de la esclavitud. ${ }^{87}$

Aunque no sabemos exactamente cuál fue la reacción en las minas, de los esclavos y manumisos que iban a ser (y fueron)

86 McGuinness, Path of Empire, p. 59.

87 Castrillón, Tomás Cipriano de Mosquera. 
trasladados a Panamá para posiblemente ser vendidos como trabajadores en el ferrocarril, es evidente que los esclavos y sus familias estaban resistiendo su venta y que éstos continuaban siendo agentes en la lucha política local. Esto también puede pensarse teniendo en cuenta el caso de los esclavos de José Antonio Arroyo mencionado y analizado arriba, quienes habían protestado en 1826 el intento de Arroyo de venderlos a Panamá diciendo: "Hoy se nos calumnia atrozmente de que somos unos esclavos alzados e incapaces de contención porque se trata de trasplantarnos de nuestro patrio suelo a otras regiones, destruyendo las cuadrillas que pueden ser muy útiles al Estado". ${ }^{88}$ Los esclavos de Esmeraldas instrumentalizaron tanto un argumento sobre su patriotismo como uno económico que los ponía en el centro del desarrollo económico de la región pacífica. Ambos puntos, por supuesto, tenían sentido y fueron estratégicos para negociar, en 1826, la protección de la cuadrilla por parte del Estado.

Además, tenemos noticias del mismo V. J. Arboleda comunicándole a T. C. de Mosquera ese mes de febrero de 1850, "que los negros están alebrestados con las ideas de libertad y hoy le escribo diciendo cuál es la verdadera libertad para ellos explicando a Ayala lo que tú propones para que los negros se animen a ir a Panamá y no crean las maldades que riegan los rojos [liberales]". ${ }^{89}$ Esto muestra que en la coyuntura de la emancipación inminente, proceso que obviamente estaba muy presente entre los esclavos y también arraigado en la lucha partidista, los esclavos buscaban que se les asegurara el bienestar y es posible que negociaran recibir la libertad en un tiempo determinado a cambio de su traslado a Panamá. Efectivamente, en el acápite 18 del contrato de T. C. de Mosquera prometía la libertad a los esclavos diciendo:

88 ANE, Esclavos, c. 23, exp. 3, 10-IV-1826. RuEdA, “Territorio, movilización e identidad étnica”, pp. 165-166.

89 Vicente Javier Arboleda a T. C. de Mosquera, Popayán, 5 de febrero, 1850. ACC, SM, 27,341. Alebrestados es sinónimo de "alborotados". 
18. Se compromete solemnemente el ciudadano-general Mosquera a nombre de la compañía su poder dataría a dar la libertad a todos los esclavos que compre en virtud de este contrato tan pronto como se concluyan los trabajos del camino y esté expedito para el tránsito interoceánico el ferrocarril. ${ }^{90}$

El tiempo en el cual se proponía liberar a los esclavos, "tan pronto como se concluyan los trabajos”, quedaba muy vagamente definido. Pero el hecho de referirse al deber de otorgarles la libertad dice mucho sobre la calidad de la negociación que debió tener lugar entre los esclavistas y los esclavos. Sus presiones se sustentaban en el contexto del triunfo del liberalismo en Nueva Granada y, también, en su conocimiento de la ley que favorecía a los esclavos dentro del marco del proyecto republicano.

\section{CONCLUSIÓN}

Este artículo demuestra por qué la abolición de la esclavitud en la América hispánica debe analizarse simultáneamente con un lente más amplio y otro más angosto que el de las historias nacionales, para incluir las dimensiones internacional y local en esas narrativas. Como en el caso estudiado en este artículo, es claro que los actores que buscaban definir los términos de la abolición -los esclavos, libres, libertos y las élites políticas en ambos lados del conflicto- eran parte de cambios en la geopolítica atlántica decimonónica.

Después de la disolución de la República de Colombia en 1831, la Nueva Granada se separó de Venezuela y del Ecuador, quedando en posesión del Istmo de Panamá. Los esclavistas payaneses, quienes tenían sus intereses principalmente en las minas de oro y aquellos que habitaban en Cali, en haciendas, continuaron su campaña para reformar la ley colombiana de manumisión

90 ACC, SM, 28,263. 
de 1821. El principal fin de esta lucha de poder era recuperar el valor de su propiedad, que estaba siendo amenazada por los mecanismos legales diseñados al momento de la fundación de la república para abolir la esclavitud gradualmente.

Las familias de esclavistas de Popayán utilizaron varias estrategias para desplegar sus ideas y sus intereses. Aprovecharon el acceso que tenían a la esfera pública para dar a conocer sus discursos y otras proclamas. También formaban parte de las instituciones del estado, tanto en el ámbito provincial como en el nacional y, desde allí, podían intervenir en la aplicación o transformación de las leyes. Más aún, tenían conexiones internacionales con otras élites esclavistas americanas, con quienes convergían alrededor de un pensamiento cosmopolita y ecléctico. Las fuentes de ese pensamiento eran textos de diverso origen, combinadas para esbozar su visión de la historia de la esclavitud tanto como de la abolición. Aunque en sus reflexiones eran centrales las referencias a los clásicos ejemplos de experiencias abolicionistas, como en Gran Bretaña o Haití, resulta muy interesante que no mencionaban los casos de Brasil o Cuba/ España. Por lo demás, la evidencia de la circulación de textos entre los esclavistas en el ámbito hispanoamericano sugiere que existió un pensamiento a favor de la esclavitud en las repúblicas del Pacífico suramericano, tal como el que han estudiado recientemente los historiadores de la "segunda esclavitud" pero que, sin embargo, no estaban directamente relacionados.

Uno de los temas más interesantes de la historia de la Nueva Granada en las décadas entre 1830 y 1850 es que el tráfico de esclavos hacia el exterior desempeñó un papel central en las estrategias políticas y económicas de los esclavistas. Posiblemente esto no es un fenómeno que se haya dado en otros lugares durante la misma época como respuesta al proceso abolicionista. Para lograr articular sus intereses, los esclavistas neogranadinos fortalecieron sus vínculos pacíficos: al sur, con Perú, y al norte con el Istmo y Estados Unidos. Incluso antes de la apertura legal 
del tráfico a través del puerto de Buenaventura en 1843, hay registros que dan luz sobre la formación de un grupo de comerciantes de esclavos minoristas, quienes tenían lazos con compradores peruanos y basaban las operaciones en procesos notariales de transferencia y compra a nivel local. Esto significa que, si bien el tráfico se había prohibido a nivel internacional, internamente no era ilegal. Y aun así, como han sugerido varios autores, este tráfico local en la región pacífica alrededor de Buenaventura también denota la existencia de un comercio exterior. ${ }^{91}$

Como sucedió paralelamente en el Perú, el impacto de la clase esclavista en la Nueva Granada demuestra la relevancia de la esclavitud en los procesos de formación del Estado en Hispanoamérica. En ambos países, durante coyunturas críticas, los esclavistas lograron manipular las instituciones del Estado y la ley en función de sus intereses. Políticamente, la legalización de la exportación de esclavos estuvo ligada a la guerra civil "de los Supremos", que potencializó el poder de la élite conservadora esclavista. Porque la movilización de las clases populares que se desató durante la misma fue evidencia irrefutable de los peligros que representaban las poblaciones de esclavizados y negros libres, los esclavistas pudieron exigir al gobierno no solamente la protección de sus intereses sino, además, un mecanismo para expulsar del territorio neogranadino a los agentes de la rebelión.

Es posible reflexionar sobre esta conexión entre el Perú y la Nueva Granada durante las décadas de 1830 y 1840 comparativamente en relación con los casos de Cuba y Haití estudiados por Ada Ferrer y el de Brasil y Uruguay analizado por Keila Grinberg en este dossier. El primero se enmarca en territorios

91 Aprile Gniset, "El Cascajal, puerto republicano y negrero"; Kitchens, “The New Granadan-Peruvian Slave Trade," p. 206, dice: “consul general in Lima reports in 1837 that slaves and manumisos from Chocó were sold as slaves to Peruvian planters in Piura". Helguera, "La exportación de esclavos en la Nueva Granada,", pp. 447-459. Véase también "Protocolo de instrumentos de 1806-1827-1832-1844", SSDA, NB. 
caribeños cuyas fronteras son diferentes a las continentales, pero comparte con la situación del Perú y la Nueva Granada el fenómeno de la articulación económica de dos procesos opuestos, el de la extinción de la esclavitud en Haití y el de su expansión en Cuba. Como lo afirma Ferrer, son procesos contrarios pero complementarios. Esta tensión, señala la misma autora, ilustra por qué es imposible hablar del siglo xix teleológicamente como el siglo de la abolición. En el caso que describe Grinberg también se oponen dos regímenes contrarios frente al tema de la legalidad de la esclavitud dando lugar a serios conflictos. Con la abolición de la esclavitud, en Uruguay se creó un "territorio libre” (free soil) y esto resultó en disputas diplomáticas cuando muchos esclavos huían del Brasil hacia Uruguay buscando su libertad. Grinberg demuestra que esa porosidad en el territorio entre Uruguay y Brasil desató una competencia por la soberanía en la frontera entre los dos países. Por otra parte, el contraste entre Nueva Granada y Perú en términos de la legalidad del tráfico de esclavos y la divergencia entre sus fines -acabar con la esclavitud en la Nueva Granda y expandirla en el Perú- resultaba beneficioso para ambos. Y la Nueva Granada no dejó de ser un "territorio libre" al legalizar la exportación de esclavos hacia el Perú. Es decir, en la Nueva Granada siguió vigente la ley que prohibía la importación de esclavos: cualquier esclavizado que llegase al territorio estaría siendo introducido ilegalmente y por lo tanto se convertiría en persona libre. ${ }^{92}$

Poner el énfasis en el activismo a favor de la esclavitud en Colombia nos permite plantear nuevas preguntas sobre la historia de la abolición en Hispanoamérica, específicamente acerca de la relación y posible interacción entre el republicanismo y la esclavitud. Esto amplía los debates sobre la era de las revoluciones

92 Ferrer, "Cuban Slavery and Atlantic Antislavery"; Ferrer, Freedom's Mirror; GrinberG, "Emancipación y guerra en el Río de la Plata, 1840-1865", que aparece en este dossier. BAUMgarTner, "Abolition from the South", trabaja el tema de la frontera entre México y Estados Unidos. 
que recientemente han sugerido que el liberalismo primó como motor de las independencias latinoamericanas, asumiendo que la abolición era un corolario inevitable del proceso. Así mismo, ofrece una mirada crítica a la narrativa anglocéntrica del siglo XIX como el “siglo de la abolición”. Si bien Gran Bretaña fue un actor relevante en el plano diplomático, el enfoque sobre el pacífico colombiano nos exige dar mayor atención a la contingencia y a ejes locales de poder, lo cual resulta en una mirada nueva, y crítica, sobre las interacciones entre Colombia y Perú, por ejemplo, y la presión británica por la abolición.

\section{SIGLAS Y REFERENCIAS}

ACC Archivo Central del Cauca, Popayán, Colombia.

ACC, AM Archivo Central del Cauca, Archivo Muerto, Popayán, Colombia.

ACC, Rep.JC Archivo Central del Cauca, República, Juicios Criminales, Popayán, Colombia.

ACC, SM Archivo Central del Cauca, Sala Mosquera, Popayán, Colombia.

ACHUN, $M A B, C O \quad$ Archivo Central e Histórico de la Universidad Nacional, fondo Manuel Ancízar Basterra, Cargos Oficiales, Bogotá, Colombia.

AGNC, C,CV Archivo General de la Nación, sección Consulados, Consulados Varios, Bogotá, Colombia.

AGNC, ALC Archivo General de la Nación, Archivo Legislativo del Congreso, Bogotá, Colombia.

AGNC, SR Archivo General de la Nación, sección República, Bogotá, Colombia.

ANE Archivo Nacional de Ecuador, fondo Esclavos, Quito, Ecuador.

AP, CC, ER Archivo de Paita, Causas Civiles, Época Republicana, Paita, Perú.

BLAA, AEDC Biblioteca Luis Ángel Arango, Archivo de Emiliano Díaz del Castillo, Bogotá, Colombia.

BNC, $P$ Biblioteca Nacional de Colombia, fondo Pineda, Bogotá, Colombia.

SSDA, NB Slave Societies Digital Archive, Notarías de Buenaventura, Vanderbilt University, Nashville TN, Estados Unidos. 
Aguirre, Carlos, Agentes de su propia libertad. Los esclavos de Lima y la desintegración de la esclavitud, 1821-1854, Lima, Pontificia Universidad Católica del Perú, 1993.

Andrews, George Reid, The Afro-Argentines of Buenos Aires, 1800-1900, Madison, University of Wisconsin Press, 1980.

Aprile Gniset, Jacques, "El Cascajal, puerto republicano y negrero", en Aprile Gniset y Mosquera Torres (coords.), 2002.

Aprile Gniset, Jacques y Gilma Mosquera Torres (coords.), Hábitats y sociedades del Pacífico, 2. Génesis de Buenaventura, Buenaventura, Universidad del Pacífico, 2002.

Arboleda, Gustavo, Diccionario biográfico y genealógico del antigno departamento del Cauca, Bogotá, Biblioteca Horizonte, 1962.

Arboleda Llorente, José María, "Venta de esclavos en Popayán”, en Popayán, 26: 271 (1959), pp. 164-167.

Bassi, Ernesto, An Aqueous Territory: Sailor Geographies and New Granada's Transimperial Greater Caribbean World, Durham, Duke University Press, 2016.

Baumgartner, Alice, "Abolition from the South: Mexico and the Road to the U.S. Civil War, 1821-1867”, tesis de doctorado en historia, New Haven, Yale University, 2018.

Beatty-Medina, Charles, "Between the Cross and the Sword: Religious Conquest and Maroon Legitimacy in Colonial Esmeraldas", en Bryant, O'Toole y VINSON III (coords.), 2012, pp. 95-113.

Bedoya Betancur, Daniel Esteban, "La controversia entre la esclavitud y la libertad. Un análisis de los discursos y debates sobre los proyectos abolicionistas en Colombia, 1814-1821", en Chaves Maldonado (coord.), 2015, pp. 119-144.

Berquist, Emily, "Early Antislavery Sentiment in the Spanish Atlantic World, 1765-1817”, en Slavery E Abolition, 31: 2 (2010), pp. 181-205.

Bethell, Leslie, The Abolition of the Brazilian Slave Trade: Britain, Brazil, and the Slave Trade Question, 1807-1869, Nueva York, Cambridge University Press, 2009. 
Bierck Jr., Harold A., “The Struggle for Abolition in Gran Colombia”, en The Hispanic American Historical Review, 33: 3 (1953), pp. 365-386.

Blackburn, Robin, "Haiti, Slavery, and the Age of Democratic Revolution", en William and Mary Quarterly, 63: 4 (2006), pp. 43-74.

Blackburn, Robin, The American Crucible: Slavery, Emancipation, and Human Rights, Nueva York, Verso, 2011.

Blanchard, Peter, Slavery and Abolition in Early Republican Peru, Wilmington, S.R. Books, 1992.

Blanchard, Peter, Under the Flags of Freedom: Slave Soldiers and the Wars of Independence in Spanish South America, Pittsburgh, Pittsburgh University Press, 2008.

Bonilla, Heraclio (coord.), Indios, negros y mestizos en la Independencia, Bogotá, Universidad Nacional de Colombia, Planeta, 2010.

Borucki, Alex, Abolicionismo y tráfico de esclavos en Montevideo tras la fundación republicana (1829-1853), Montevideo, Ediciones Biblioteca Nacional, 2009.

BRAGONI, Beatriz, "Esclavos insurrectos en tiempos de la revolución (Cuyo 1812)”, en Mallo y Telesca (coords.), 2010, pp. 113-120.

Bryant, Sherwin, Rachel O’Toole y Ben Vinson III (coords.), Africans to Spanish America: Expanding the Diaspora, Chicago, Illinois University Press, 2012.

Calarge, Carla, Raphael Dalleo, Luis Duno-Gottberg y Clevis Headle (coords.), Haiti and the Americas, Jackson, University Press of Mississippi, 2013.

Castellanos, Jorge, La abolición de la esclavitud en Popayán, 1832-1852, Cali, Universidad del Valle, 1980.

Castillio, Celso, Slave Emancipation and Transformations in Brazilian Political Citizenship, Pittsburgh, Pittsburgh University Press, 2016.

Castrillón, Diego, Tomás Cipriano de Mosquera, Bogotá, Planeta, 1994. 
Chaves Maldonado, María Eugenia (coord.), Los "otros" de las independencias, los "otros" de la nación. Participación de la población afrodescendiente e indígena en las independencias del Nuevo Reino de Granada, Chile y Haití, Medellín, Universidad Nacional de Colombia sede Medellín, 2015.

Clementi, Hebe, La abolición de la esclavitud en América Latina, Buenos Aires, La Pléyade, 1974.

Colmenares, Germán, Historia económica y social de Colombia, vol. II. Popayán: una sociedad esclavista, 1680-1800, 1979, Bogotá, Tercer Mundo Editores, 1999.

DíAz, María Camila, Salteadores y cuadrillas de malhechores: una aproximación a la acción colectiva de la 'población negra' en el suroccidente de la Nueva Granada, 1840-1851, Popayán, Universidad del Cauca, 2015.

DíAz, Zamira, "El Cauca Grande en el proyecto de construcción de la nación neogranadina (1832-1858)", en Anuario de Historia Regional y de las Fronteras, 6: 1 (2001), pp. 163-199.

DRESCHER, Seymour, Abolition: A History of Slavery and Antislavery, Nueva York, Cambridge University Press, 2009.

Dubois, Laurent, Avengers of the New World: The Story of the Haitian Revolution, Cambridge, MA, Belknap Press, 2004.

Dumas, Paula, Proslavery Britain: Fighting for Slavery in an Era of Emancipation, Nueva York, Palgrave, 2016.

ECHEVERRI, Marcela, “'Enraged to the Limit of Despair': Infanticide and Slave Judicial Strategies in Barbacoas, 1788-1798”, en Slavery \& Abolition, 30: 3 (2009), pp. 403-426.

ECHEVERri, Marcela, Indian and Slave Royalists in the Age of Revolution: Reform, Revolution, and Royalism in the Northern Andes, 1780-1825, Cambridge, Cambridge University Press, 2016.

Echeverri, Marcela, "Slavery in Mainland Spanish America in the Age of the Second Slavery", en Dale Tомісн (coord.), Atlantic Transformations in the Age of the Second Slavery, Binghamton, N.Y, Fernand Braudel Series, sunY Press, en prensa. 
Feliú Cruz, Guillermo, La abolición de la esclavitud en Chile, Santiago de Chile, Editorial Universitaria, 1973.

Ferrer, Ada, "Haiti, Free Soil, and Antislavery in the Revolutionary Atlantic", en American Historical Review, 117: 1 (2012), pp. 40-66.

Ferrer, Ada, "Cuban Slavery and Atlantic Antislavery", en Fradera y SCHMIDT-Nowara (coords.), 2013, pp. 134-157.

FERrer, Ada, Freedom's Mirror: Cuba and Haiti in the Age of Revolution, Nueva York, Cambridge University Press, 2014.

Fischer, Sibylle, "Bolívar in Haiti: Republicanism in the Revolutionary Atlantic”, en Calarge, Dalleo, Duno-Gottberg y Headle (coords.), 2013, pp. 25-53.

Fradera, Josep y Christopher Schmidt-Nowara (coords.), Slavery and Antislavery in Spain's Atlantic Empire, Nueva York, Berghahn, 2013.

Gharala, Norah L.A., Taxing Blackness: Afromexican Tribute in Bourbon New Spain, Tuscaloosa, University of Alabama Press, 2019.

Genovese, Eugene, The Slaveholders' Dilemma: Freedom and Progress in Southern Conservative Thought, 1820-1860, Columbia, University of South Carolina Press, 1992.

Goldberg, Marta Beatriz, "Afrosoldados de Buenos Aires en armas para defender a sus amos”, en Mallo y Telesca (coords.), 2010, pp. 39-64.

Gootenberg, Paul, Between Silver and Guano: Commercial Policy and the State in Postindependence Peru, Princeton, Princeton University Press, 1989.

Helg, Aline, Liberty and Equality in Caribbean Colombia, 1770-1835, Chapel Hill, University of North Carolina Press, 2004.

Helguera, J. León, "La exportación de esclavos en la Nueva Granada”, en Archivos, 1: 1 (1967), pp. 447-459.

HünEFELDT, Christine, Paying the Price of Freedom: Family and Labor among Lima's Slaves, 1800-1854, Berkeley, University of California Press, 1994.

Huzzey, Richard, Freedom Burning: Anti-slavery and Empire in Victorian Britain, Ithaca, Cornell University Press, 2012. 
JARAMILlo URIBE, Jaime, "La controversia jurídica y filosófica librada en la Nueva Granada en torno a la liberación de los esclavos y la importancia económica y social de la esclavitud en el siglo xix", en Ensayos de Historia Social, t. I. La sociedad neogranadina, Bogotá, Tercer Mundo Editores, 1989, pp. 217-250.

KaYe, Anthony, "The Second Slavery: Modernity in the Nineteenth-Century South and the Atlantic World", en Journal of Southern History, 75: 3 (2009), pp. 627-650.

KING, James Ferguson, “The Latin-American Republics and the Suppression of the Slave Trade", en The Hispanic American Historical Review, 24: 3 (1944), pp. 387-411.

Kitchens, John, “The New Granadan-Peruvian Slave Trade”, en Journal of Negro History, 64: 3 (1979), pp. 205-215.

Kitchens, John y J. León Helguera, “Los vecinos de Popayán y la esclavitud en la Nueva Granada”, en Boletin de Historia y Antigüedades, LXIII: 713 (1976), pp. 219-239.

KITCHEns, John y Lynne Kitchens, "La exportación de esclavos neogranadinos en 1846 y las reclamaciones británicas”, en Boletín de Historia y Antigüedades, LXIII: 713 (1976), pp. 239-293.

Konetzke, Richard, Colección de documentos para la formación social de Hispanoamérica 1493-1810, III: 2, Madrid, Consejo Superior de Investigación Científica, 1962.

Landers, Jane, "Cimarrón and Citizen: African Ethnicity, Corporate Identity, and the Evolution of Free Black Towns in the Spanish Circum-Caribbean", en LANDERS y ROBINSON (coords.), 2006, pp. 111-146.

Landers, Jane y Barry Robinson (coords.), Slaves, Subjects, and Subversives: Blacks in Colonial Latin America, Albuquerque, University of New Mexico Press, 2006.

Lasso, Marixa, Myths of Harmony: Race and Republicanism during the Age of Revolution, Colombia 1795-1831, Pittsburgh, University of Pittsburgh Press, 2007.

Lombardi, John, The Decline and Abolition of Negro Slavery in Venezuela, 1820-1854, Westport, Greenwood Publishing Corporation, 1971. 
Lynch, John, Simón Bolivar: A Life, New Haven, Yale University Press, 2006.

Mallo, Silvia e Ignacio Telesca (coords.), "Negros de la patria": los afrodescendientes en las luchas por la independencia en el antiguo Virreinato del Río de la Plata, Buenos Aires, SB, 2010.

Marquese, Rafael, Tâmis Parron y Márcia Berbel, Slavery and Politics: Brazil and Cuba, 1790-1850, traducción de Leonardo Marques, Albuquerque, University of New Mexico Press, 2016.

Marzahl, Peter, "Creoles and Government: The Cabildo de Popayán”, en The Hispanic American Historical Review, 54 (1974), pp. 636-656.

Mata, Sara, "Negros y esclavos en la guerra por la independencia. Salta 18101821”, en Mallo y Telesca (coords.), 2010, pp. 131-147.

McGreevy, William, An Economic History of Colombia, 1845-1930, Cambridge, Cambridge University Press, 1971.

McGuiness, Aimes, Path of Empire: Panama and the California Gold Rush, Ithaca, Cornell University Press, 2008.

Mosquera, Joaquín, Memoria sobre la necesidad de reformar la ley del Congreso Constituyente de Colombia de 21 de julio de 1821, que sancionó la libertad de los partos, manumisión y abolición del tráfico de esclavos, Bogotá, Impreso por F. M. Stokes, 1825.

Mosquera, José Rafael, Proyecto de ley sobre manumisión de esclavos e indemnización a los amos (1824), Biblioteca Nacional de Colombia, Fondo Pineda, tomo 36, cuaderno 16.

Nash, Gary y Jean Soderlund, Freedom by Degrees: Emancipation in Pennsylvania and its Aftermath, Nueva York, Oxford University Press, 1991.

Pando, José María, Reclamación de los vulnerados derechos de los hacendados de las provincias litorales del departamento de Lima, Lima, Imprenta de J. M. Concha, 1833, Beinecke Library, Peruvian Pamphlets 54.

Peru de Lacroix, Louis, Diario de Bucaramanga. Vida pública y privada del libertador, 1869, Caracas, Ediciones Centauro, 1976.

Pita Pico, Roger, La manumisión de esclavos en el proceso de intendencia de Colombia: realidades, promesas y desilusiones, Bogotá, Kimpres, 2014. 
Posada, Eduardo y Carlos Restrepo Canal, La libertad de los esclavos en Colombia y leyes de manumisión, Bogotá, Imprenta Nacional, 1935.

Prado Arellano, Luis Ervin, Rebeliones en la provincia. La guerra de los supremos en las provincias suroccidentales y nororientales granadinas, 18391842, Popayán, Universidad del Cauca, 2007.

Prado, Luis Ervin y David Fernando Prado-Valencia, "La familia Mosquera y Arboleda y el proyecto bolivariano (1821-1830)", en Memoria y Sociedad, 14: 29 (2010), pp. 55-69.

RuEDA, Rocío, “Territorio, movilización e identidad étnica: participación de los esclavizados del norte de Esmeraldas en las guerras de independencia, 18091813”, en Bonilla (coord.), 2010, pp. 125-127.

Rugemer, Edward, "The Development of Mastery and Race in the Comprehensive Slave Codes of the Greater Caribbean during the Seventeenth Century”, en William and Mary Quarterly, 70: 3 (2013), pp. 429-458.

SAFFORD, Frank, "Social Aspects of Politics in Nineteenth-Century Spanish America: New Granada, 1825-1850”, en Journal of Social History, 5: 3 (1972), pp. 344-370.

SAFFord, Frank, The Ideal of the Practical: Colombia's Struggle to Form a Technical Elite, Austin, University of Texas Press, 1976.

Sharp, William, Slavery on the Spanish Frontier: The Colombian Choco, 16801810, Oklahoma, Norman, 1976.

Simon, Joshua, The Ideology of Creole Revolution: Imperialism and Independence in American and Latin American Political Thought, Nueva York, Cambridge University Press, 2017.

TARDIEU, Jean-Pierre, El decreto de Huancayo: la abolición de la esclavitud en el Perú, Lima, Fondo Editorial del Congreso del Perú, 2004.

Temperley, Howard, British Antislavery, 1833-1870, Londres, Longman, 1972.

Tobar Donoso, Julio, "La abolición de la esclavitud en el Ecuador", en Boletín de la Academia Nacional de Historia, 34: 93 (1959), pp. 5-38. 
Tomich, Dale W. (coord.), The Politics of the Second Slavery, Ithaca, State University of New York Press, 2016.

Torres, Gerónimo, Observaciones de G. T. sobre la Ley de manumisión del Soberano Congreso de Colombia, Bogotá, Impreso por José Manuel Galagarza, 1822.

Tovar, Jorge Andrés y Hermes Tovar, El oscuro camino de la libertad. Los esclavos en Colombia, 1821-1851, Bogotá, Universidad de Los Andes, 2009.

Townsend, Camilla, "En busca de la libertad. Los esfuerzos de los esclavos gualaquileños por garantizar su independencia después de la independencia”, en Revista PROCESOS, 4 (1993), pp. 73-85.

Trouillot, Michel-Rolph, Silencing the Past: Power and the Production of History, Boston, Beacon Press, 1995.

Uribe-Urán, Víctor, Honorable Lives: Lawyers, Family, and Politics in Colombia 1780-1850, Pittsburgh, Pittsburgh University Press, 2000.

Valencia Llano, Alonso, Dentro de la ley, fuera de la ley. Resistencias sociales y politicas en el valle del río Canca, 1830-1855, Cali, Universidad del Valle, 2008.

Verna, Paul, Pétion y Bolivar. Cuarenta años (1790-1830) de relaciones haitianovenezolanas y su aporte a la emancipación de Hispanoamérica, Caracas, Imprenta Nacional, 1969.

West, Robert, Colonial Placer Mining in Colombia, Baton Rouge, Louisiana State University Press, 1952.

Wright, Gavin, Slavery and American Economic Development, Baton Rouge, Louisiana State University Press, 2013. 
